\title{
AVALIAÇÃO DO AMBIENTE DE CONTROLE INTERNO POR MEIO DE MODELO DE MATURIDADE EM ORGANIZAÇÕES GOVERNAMENTAIS $\left({ }^{1}\right)$
}

\author{
INTERNAL CONTROL ENVIRONMENT EVALUATION BY \\ MEANS OF MATURITY MODEL IN GOVERNMENT \\ ORGANIZATIONS
}

\section{EVALUACIÓN DE ENTORNO DE CONTROL INTERNO POR MEDIO DE MODELO DE MADUREZ EN ORGANIZACIONES DE GOBIERNO}

\author{
Ricardo Augusto Capovilla \\ Mestre em Ciências Contábeis pelo \\ Programa Multi-institucional e Inter-regional \\ de Ciências Contábeis UnB, UFPB, UFRN, \\ Brasil / Auditor Federal de Controle Externo \\ do Tribunal de Contas da União, Brasília, \\ Brasil \\ ricardo_capovilla@hotmail.com
}

\section{Rodrigo de Souza Gonçalves}

Doutor em Ciências Contábeis pelo Programa Multi-institucional e Inter-regional de Ciências Contábeis UnB, UFPB, UFRN, Brasil / Professor do Programa de Pósgraduação em Ciências Contábeis da Universidade de Brasília, Brasil rgoncalves@unb.br
Contextus

ISSNe 2178-9258

Organização: Comitê Científico Interinstitucional Editor Científico: Diego de Queiroz Machado

Avaliação: double blind review pelo SEER/OJS Edição de texto e de layout: Carlos Daniel Andrade

Recebido em 21/09/2017

Aceito em 30/05/2018

$2^{\underline{a}}$ versão aceita em 21/06/2018

\section{RESUMO}

O objetivo do trabalho foi avaliar a maturidade do ambiente de controle interno em organizações governamentais. Foi desenvolvido um modelo de maturidade sustentado nos princípios do COSO (2013a) estruturado em quatro níveis de maturidade: incipiente, inicial, em formação e estabelecido. O modelo foi avaliado por juízes (COY; DIXON, 2004) e testado em três organizações governamentais por meio de estudo de casos múltiplos. Os resultados apontaram que uma das entidades alcançou o nível de maturidade inicial, enquanto as demais, o nível de maturidade em formação. No todo, as três organizações revelaram incipiência quanto à maturidade do ambiente de controle, especialmente na disseminação de padrões de ética e na investigação de vida pregressa e requisitos de competência para o corpo diretivo. Por fim, o estudo apontou de forma comparada aspectos necessários para melhoria das estruturas do ambiente de controle interno de cada organização, podendo ser útil aos respectivos gestores e órgãos de controle.

Palavras-chave: Ambiente de controle; Modelo de maturidade; Administração pública; INCRA; MAPA; CONAB.

\footnotetext{
ABSTRACT

This work aimed to evaluate how mature the internal control environment is in governmental organizations. A maturity model was developed based on the principles of COSO (2013a), being structured into four levels of maturity: incipient, initial, developing and established. The model was assessed by judges (COY; DIXON, 2004) and tested in three governmental organizations by means of multiple-case studies. Just as indicated by results,

${ }^{1}$ Os autores agradecem pelo auxílio financeiro à pesquisa por parte da Secretaria de Coordenação e Governança das Empresas Estatais (SEST/MP), do Ministério do Planejamento, Desenvolvimento e Gestão.
} 
one of the entities reached the initial maturity level, while the others reached the developing maturity level. Overall, the three organizations revealed incipience as to the maturity of the control environment, especially in spreading ethical standards and in due diligence and competency requirements for the governing body. Finally, the study points out, in a comparative way, aspects necessary to improve the internal control environment structures of each organization and can be useful to the respective managers and control bodies.

Keywords: Control environment; Maturity model; Public Administration; INCRA; MAPA; CONAB.

\section{RESUMEN}

El objetivo del trabajo fue evaluar la madurez del entorno de control interno en organizaciones gubernamentales. Se desarrolló un modelo de madurez sostenido en principios del COSO (2013a) y estructurado en cuatro niveles de madurez: incipiente, inicial, en desarrollo y establecido. El modelo fue evaluado por jueces (COY; DIXON, 2004) y se probó en tres organizaciones gubernamentales por estudio de casos múltiples. Los resultados apuntan que una entidad alcanzó el nivel de madurez inicial, mientras que las demás, el nivel de madurez en desarrollo. En total, las tres organizaciones revelaron incipiente madurez del entorno de control, en especial en diseminación de códigos de ética y en debida diligencia y requisitos de competencia para el consejo de administración. Por último, el estudio apunta de forma comparada aspectos necesarios para mejorar las estructuras de entorno de control de cada organización, pudiendo ser útil a los respectivos gestores y órganos de control.

Palabras clave: Entorno de control; Modelo de madurez; Administración publica; INCRA; MAPA; CONAB.

\section{CONTEXTUALIZAÇÃO}

De 2011 a 2015, a política econômica buscou o crescimento ao estimular tanto o consumo das famílias, com o aumento real do salário mínimo e a redução da taxa básica de juros, quanto o investimento do setor privado, com desonerações, redução de custos e facilitação de financiamentos. Tal política, associada à expansão dos gastos governamentais, levou o Brasil a um cenário de crise econômica e fiscal (MARTINS, 2015). Além disso, a revelação de esquemas de corrupção e de fraudes, com desvio de recursos públicos em diversas organizações governamentais brasileiras, fomentou um cenário de insatisfação social, alimentando a crise política vivida pelo país (LOPES JUNIOR et al., 2018).

Esse contexto aumenta a pressão para que o estado brasileiro reduza seus gastos, tornando-se mais eficiente e eficaz, e desenvolva mecanismos para que a gestão de suas entidades seja mais transparente e condizente com os interesses dos cidadãos (FILGUEIRAS, 2018). Aprimorar as estruturas de controle interno das organizações governamentais vai ao encontro das demandas da sociedade.

Segundo o Committee of Sponsoring Organizations of the Treadway Commission COSO (2013a), controle interno (CI) é "um processo conduzido pelo corpo diretivo, gerência e outros profissionais da entidade, e desenvolvido para proporcionar segurança razoável com respeito à realização dos objetivos relacionados às operações, divulgação e conformidade"i. Os frameworks de CI e boas práticas associadas (COSO, 2013a; GAO, 2001; GAO, 2014) auxiliam gestores e auditores a implantar e avaliar a eficácia dos CI de uma organização, ao 
definir os componentes de um sistema de controle e um conjunto de princípios necessários para tal sistema garantir à organização, em grau razoável, que seus objetivos sejam realizados e suas informações financeiras estejam livres de distorções relevantes.

Os CI são normalmente avaliados, quanto a sua eficácia e ao risco de auditoria, com base em padrões que orientam o trabalho do auditor. Como resultado, os relatórios de auditoria, em especial na área pública, ocasionalmente destacam as fragilidades dos CI sem contudo estabelecer uma orientação evolutiva de quais providências devem ser tomadas ou permitir que se aproveitem experiências de outras entidades.

Nesse cenário, o presente estudo teve por objetivo analisar o ambiente de controle interno em organizações públicas por meio de um modelo de maturidade. Este pode ser definido como "um conjunto estruturado de elementos que descrevem as características de processos eficazes em diferentes estágios de desenvolvimento" (PULLEN, 2007, p. 9). Tal modelo estabelece um caminho evolutivo antecipado, desejado ou típico (BECKER et al., 2009) e serve aos propósitos de diagnóstico, evolução e comparação das capacidades daqueles processos (PÖPPELBUß; RÖGLINGER, 2011).

Portanto, foi oportuno este estudo ter analisado o ambiente de CI por meio de um modelo de maturidade, sustentado no COSO revisado (2013a) e em padrões do GAO - United States General Accountability Office (GAO, 2001; 2014). Com isso, possibilitou propor ao gestor público tanto ações prescritivas relativas à implantação, condução e avaliação de melhorias em sua estrutura de CI, quanto a comparação de resultados com outras entidades (RUBINO; VITOLLA; GARZONI, 2017). As propostas podem inclusive ser utilizadas por órgãos de supervisão e controle, possibilitando melhorias na elaboração de seus relatórios.

\section{REFERENCIAL TEÓRICO}

Hay (1993) afirma que o conceito de CI foi incluído nos padrões profissionais de auditoria dos países de língua inglesa nas décadas de 1920 e 1930, evoluindo a partir dos anos 1950, principalmente em razão: de críticas públicas a procedimentos de auditoria que antecederam falências de companhias; da resistência dos auditores à expansão de suas responsabilidades; e da crescente padronização dos termos aplicados para definição.

Essa evolução permitiu aos procedimentos de auditoria serem atualmente realizados com base em frameworks como a Orientação Turnbull (Reino Unido), a Orientação sobre 
Controles do CoCo (Canadá), o padrão de auditoria do AICPA (SAS nº 78), o ITGI (2007), o GAO (2001; 2014) e o COSO (2013a, 2013b). Os mencionados frameworks estabelecem princípios e conceitos que norteiam a atividade de auditoria, seja nas organizações privadas, seja nas públicas, em especial na avaliação das estruturas de CI.

Para o American Institute of Certified Public Accountants (AICPA), a estrutura de CI é definida como "as políticas e procedimentos estabelecidos para prover segurança razoável de que os objetivos específicos da entidade serão realizados"ii (AICPA, 1988, p. 4, apud HAY, 1993). Segundo Fadzil, Haron e Jantan (2005), somente um controle adequado pode assegurar que os objetivos e metas previamente estabelecidas serão alcançados. Spira e Page (2003), por sua vez, complementam que a tarefa de conhecer o risco das atividades internas e mitigá-las deve ser um dos aspectos a serem desenvolvidos por meio das atividades de controle interno e da auditoria, enquanto Bernardi (1994) defende para esse aspecto um caráter fundamental no planejamento e condução das atividades de auditoria.

Assim, para tais objetivos serem alcançados, o COSO (2013a) propõe cinco componentes da estrutura de CI: ambiente de controle; avaliação de riscos; atividades de controle; informação e comunicação; e monitoramento. Cada componente possui um conjunto de princípios que auxilia a compreensão de seu conteúdo e orienta os esforços de desenvolvimento do componente.

Dentre esses componentes destaca-se o ambiente de controle. Segundo o COSO (2013a) ambiente de controle "é o conjunto de padrões, processos e estruturas que proveem a base para a realização do controle interno ao longo da organização", e sua relevância é notória, segundo Whittington e Pany (2012), na medida em que estabelece as bases para a eficácia de uma estrutura de CI. Para Rubino, Vitolla e Garzoni (2017) um adequado ambiente de CI induz a um comportamento ético, íntegro e moral das pessoas para com a organização.

Segundo Johnstone et al. (2012), as deficiências no ambiente de controle, por sua vez, estão normalmente associadas, sobretudo, às fraudes financeiras, no caso de conselhos de administração dominados pela alta gerência que não exerciam adequadamente a supervisão. São exemplos: baixo nível de consciência de controle na organização; comitê de auditoria que não tem membros independentes; falta de cobrança de um comportamento ético na organização; administração que burla os controles sobre as transações contábeis e pessoal sem competência para cumprir suas atribuições (JOHNSTONE et al., 2012). 
Para tanto, o arcabouço conceitual acerca do ambiente de CI (COSO, 2013a; COSO, 2013b; GAO, 2014), combinado com a lógica dos modelos de maturidade (BECKER et al., 2009; PÖPPELBUß; RÖGLINGER, 2011; RUBINO; VITOLLA; GARZONI, 2017), pode ser útil para a avaliação, análise e prescrição de melhores práticas em estruturas de CI. Segundo Rubino, Vitolla e Garzoni (2017), à medida que as organizações dispõem de processos internos desenhados com base na lógica de um modelo de maturidade, eles podem ajudar os gestores e auditores a dispor de uma melhor avaliação de seu ambiente de controle. Para Exner, Zimpfer e Stark (2017), o primeiro passo, nesse contexto, é avaliar o estágio atual em que se encontra a organização, para assim desenvolver um plano estratégico tendo em vista o caminho desejado, o que pode se realizar com os modelos de maturidade.

A contribuição de um modelo de maturidade, segundo Becker et al. (2009, p. 1), é que ele "consiste em uma sequência de níveis de maturidade para uma classe de objetos [...], representa o caminho de evolução antecipado, desejado ou típico desses objetos formatado em fases distintas. Normalmente, esses objetos são organizações ou processos’iii. Pöppelbuß e Röglinger (2011) acrescentam que modelos de maturidade são conhecidos também como modelos de estágios de crescimento, modelos de estágios ou teorias de estágios.

Ao comparar os propósitos dos modelos de maturidade e dos padrões de auditoria isoladamente, eles se diferenciam. Os padrões de auditoria buscam estabelecer procedimentos para minimizar o risco de que o auditor expresse uma opinião de auditoria inadequada (HAY, 1993; COSO, 2013a). Nesse escopo, uma estrutura de controle ineficaz aumenta a incerteza quanto: à eficiência e eficácia das operações; à conformidade com as leis e regulamentos aplicáveis; e à ausência de distorções materialmente relevantes nas informações financeiras da entidade. Assim, o risco de auditoria é maior e o auditor deve realizar procedimentos adicionais para obter evidências que deem embasamento mais seguro à sua opinião (JOHNSTONE et al., 2012).

Já o modelo de maturidade tem o propósito de auxiliar auditores e gestores a classificarem estruturas de CI conforme suas capacidades (RUBINO; VITOLLA; GARZONI, 2017), possibilitando a comparação entre as estruturas de diferentes organizações e apresentando um caminho evolutivo que orienta a organização quanto às providências necessárias para obter um nível de maturidade ideal. A comparação proporcionada pelos modelos de maturidade pode estimular a melhoria tanto das organizações do setor governamental, que tendem a tornar-se mais eficientes e eficazes, quanto da gestão pública, 
que tende a ganhar maior transparência e a alinhar-se com os interesses e objetivos organizacionais e da sociedade.

Nesse sentido, um modelo de maturidade que avalie o ambiente de controle pode auxiliar a organização a compreender as capacidades atuais de sua estrutura de CI, permitindo identificar as providências de melhoria própria e comparar-se com outras entidades, podendo criar um ciclo virtuoso de troca de boas práticas e de melhoria contínua (RUBINO; VITOLLA; GARZONI, 2017; RUBINO; VITOLLA, 2014).

\section{PERCURSO METODOLÓGICO}

Este estudo tem natureza qualitativa. Quanto à tipologia, trata-se de pesquisa descritiva e documental (RICHARDSON et al., 2015). Os documentos utilizados para avaliação do ambiente de controle encontram-se listados no Apêndice 1. A análise dos dados foi realizada com base nos princípios da análise de conteúdo (BARDIN, 2011), a partir dos critérios estabelecidos no modelo de maturidade, cujo detalhamento encontra-se nos itens 3.1 a 3.3 a seguir.

\subsection{Elaboração do instrumento de pesquisa}

O instrumento de pesquisa foi elaborado com base nos princípios do COSO (2013a e 2013b) e nos padrões do U. S. Government Accountability Office - GAO (2014), permitindo estabelecer as subdimensões do ambiente de controle: (a) Padrões de Conduta; (b) Independência e Competência do Corpo Diretivo; (c) Responsabilidades de Controle Interno e Requisitos de Competência; (d) Atração, Desenvolvimento e Retenção de Indivíduos; e (e) Avaliação de Desempenho. Essas subdimensões e suas respectivas variáveis são apresentadas a seguir. 
Quadro 1 - Avaliação do ambiente de controle

\begin{tabular}{|c|c|c|}
\hline Dimensão & Subdimensão & Variável \\
\hline \multirow{13}{*}{$\begin{array}{l}\text { Ambiente de } \\
\text { controle } \\
\text { (COSO, } \\
\text { 2013a; } \\
\text { COSO, } \\
\text { 2013b) }\end{array}$} & \multirow{3}{*}{$\begin{array}{l}\text { Padrões de Conduta } \\
\text { (COSO, 2013a; COSO, } \\
\text { 2013b) }\end{array}$} & $\begin{array}{l}\text { Destinatários dos Padrões de Conduta } \\
\text { (COSO, 2013a; COSO, 2013b) }\end{array}$ \\
\hline & & $\begin{array}{l}\text { Disseminação dos Padrões de Conduta, Ética e } \\
\text { Valores (COSO, 2013a; COSO, 2013b) }\end{array}$ \\
\hline & & $\begin{array}{l}\text { Estrutura Organizacional para Aderência aos } \\
\text { Padrões de Conduta (COSO, 2013a; COSO, } \\
\text { 2013b) }\end{array}$ \\
\hline & \multirow{2}{*}{$\begin{array}{l}\text { Independência } \\
\text { Competência do Corpo } \\
\text { Diretivo } \\
\text { (COSO, 2013a; COSO, } \\
\text { 2013b; GAO, 2014) }\end{array}$} & $\begin{array}{l}\text { Políticas de Investigação de Vida Pregressa } \\
\text { para o Corpo Diretivo (COSO, 2013a; COSO, } \\
\text { 2013b) }\end{array}$ \\
\hline & & $\begin{array}{l}\text { Requisitos de Competência do Corpo Diretivo } \\
\text { (COSO, 2013a; COSO, 2013b) }\end{array}$ \\
\hline & \multirow{2}{*}{$\begin{array}{l}\text { Responsabilidades } \\
\text { Controle Interno } \\
\text { Requisitos } \\
\text { Competências } \\
\text { (COSO, 2013a; COSO, } \\
\text { 2013b) }\end{array}$} & $\begin{array}{l}\text { Responsabilidades de Controle Interno na } \\
\text { Organização } \\
(\text { COSO, 2013a; COSO, 2013b) } \\
\end{array}$ \\
\hline & & $\begin{array}{l}\text { Requisitos de Competências na Organização } \\
\text { (COSO, 2013a; COSO, 2013b) }\end{array}$ \\
\hline & $\begin{array}{l}\text { Atração, } \\
\text { Desenvolvimento } \\
\text { Retenção de Indivíduos } \\
\text { (COSO, 2013a; COSO, } \\
\text { 2013b) }\end{array}$ & $\begin{array}{l}\text { Programa de Desenvolvimento } \\
\text { Competências } \\
(\text { COSO, 2013a; COSO, 2013b) }\end{array}$ \\
\hline & \multirow{5}{*}{$\begin{array}{l}\text { Avaliação } \\
\text { Desempenho } \\
\text { (COSO, 2013a; COSO, } \\
\text { 2013b; GAO, 2014) }\end{array}$} & $\begin{array}{l}\text { Fatores da Avaliação de Desempenho } \\
\text { (COSO, 2013a; COSO, 2013b) }\end{array}$ \\
\hline & & $\begin{array}{l}\text { Níveis Organizacionais da Avaliação de } \\
\text { Desempenho de Desempenho (COSO, 2013a; } \\
\text { COSO, 2013b) }\end{array}$ \\
\hline & & $\begin{array}{l}\text { Níveis Organizacionais das Metas de } \\
\text { Desempenho (COSO, 2013a; COSO, 2013b) }\end{array}$ \\
\hline & & $\begin{array}{l}\text { Recompensas e Sanções da Avaliação de } \\
\text { Desempenho (COSO, 2013a; COSO, 2013b) }\end{array}$ \\
\hline & & $\begin{array}{l}\text { Frequência da Avaliação de Desempenho } \\
\text { (GAO, 2001; COSO, 2013b) }\end{array}$ \\
\hline
\end{tabular}

Fonte: elaborado pelos autores (2015).

Com base no que o COSO (2013a) define como CI, verifica-se que a lógica de evolução possui diferentes pontos de alavancagem da mudança, as quais incluem: a) estrutura organizacional; b) políticas, processos e procedimentos; e c) pessoas. Portanto, a par tanto da complexidade do modelo de maturidade pretendido, quanto da ideia ainda incipiente a respeito da evolução da maturidade das variáveis ora utilizadas e boas práticas de CI, a escala utilizada busca representar estágios de um processo de implantação de uma estrutura de CI relativo ao ambiente de controle, definida conforme a seguir: (0) Incipiente; (1) Inicial; (2) Em formação; e (3) Estabelecido. 
Depois de definir os níveis de maturidade, foram elaborados os critérios de enquadramento de cada nível, dentro de cada variável da proposta. Os critérios foram elaborados com base nas boas práticas de CI relacionadas a cada variável, propondo uma lógica evolutiva em termos de complexidade, abrangência, detalhamento, integração, periodicidade e automatização para o objeto de cada variável. Para caracterizar os níveis de maturidade em cada uma das variáveis, utilizaram-se as métricas de boas práticas de CI estabelecidas pelo COSO (2013b) e GAO (2001), bem como os critérios do modelo de maturidade do Cobit (ITGI, 2007). A descrição dos critérios estabelecidos para cada variável está evidenciada na seção 3.3 .

\subsection{Pré-teste do instrumento de pesquisa}

O modelo de maturidade proposta foi submetido a procedimento de pré-teste, com a avaliação de especialistas, com o objetivo de obter contribuições para aperfeiçoar a clareza e a pertinência das variáveis e dos critérios de enquadramento em cada nível de maturidade (COY; DIXON, 2004). Os especialistas foram selecionados do quadro de Auditores Federais de Controle Externo do Tribunal de Contas da União, com conhecimento e experiência em CI, identificados em seus currículos, conforme cadastro no sistema de gestão de competências do TCU.

Em uma escala de 1 a 5 (5=totalmente pertinente ou claro), os aspectos relativos à clareza das variáveis obteve uma média de 3,67 e, quanto à pertinência, uma média de 4,60. As críticas e sugestões de cada especialista foram integradas ao modelo utilizado para avaliar a maturidade do ambiente de CI das entidades que participaram deste estudo.

\subsection{Diagnóstico da maturidade do ambiente de controle das entidades}

Participaram deste estudo 3 organizações públicas em entidades com diferentes funções na Administração pública, diferentes estruturas organizacionais e de governança - o Ministério da Agricultura, Pecuária e Abastecimento (MAPA), o Instituto Nacional de Colonização e Reforma Agrária (INCRA) e a Companhia Nacional de Abastecimento $(\mathrm{CONAB})$ - com objetivo de avaliar a aderência e validade do instrumento de pesquisa (modelo de maturidade) (OLLAIK; ZILLER, 2012; MINAYO, 2009). 
O diagnóstico para o nível de maturidade do ambiente de controle baseou-se em elementos obtidos ao analisar documentos fornecidos pelas entidades estudadas. Os elementos foram comparados com os critérios de enquadramento em cada uma das variáveis do modelo de maturidade, e o resultado foi tipificado conforme a descrição no quadro a seguir.

Quadro 2 - Tipificação do atendimento aos critérios de enquadramento das variáveis do ambiente de controle

\begin{tabular}{|l|l|}
\hline Juízo & Características \\
\hline $\begin{array}{l}\text { Sim } \\
(100 \%)\end{array}$ & $\begin{array}{l}\text { As evidências encontradas na análise foram consideradas suficientes para afirmar } \\
\text { que ombiente de controle da entidade atende integralmente ao critério definido. }\end{array}$ \\
\hline $\begin{array}{l}\text { Parcial } \\
(50 \%)\end{array}$ & $\begin{array}{l}\text { A análise identificou quer evidências de que o ambiente de controle da entidade } \\
\text { atende apenas parcialmente ao critério definido, quer indícios de atendimento ao } \\
\text { critério, porém insuficientes para afirmar que o critério foi atendido integralmente. }\end{array}$ \\
\hline $\begin{array}{l}\text { Não } \\
(0 \%)\end{array}$ & $\begin{array}{l}\text { A análise ou não identificou evidências de que o ambiente de controle da entidade } \\
\text { atenda ao critério definido, ou identificou evidências suficientes para afirmar que o } \\
\text { ambiente de controle da entidade não atende ao critério definido. }\end{array}$ \\
\hline
\end{tabular}

Fonte: procedimentos da pesquisa (2016).

O Quadro 3 exemplifica o procedimento de avaliação do atendimento aos critérios de enquadramento das variáveis, conforme a tipificação do Quadro 2. A avaliação demonstrada no Quadro 3 foi realizada para cada uma das variáveis do ambiente de controle.

Quadro 3 - Exemplo de avaliação de atendimento aos critérios de enquadramento: variável Níveis Organizacionais da Avaliação de Desempenho

\begin{tabular}{|l|l|l|l|l|l|}
\hline \multirow{2}{*}{ Nível } & Critério & \multicolumn{3}{|l|}{ Exemplos de avaliação } \\
\cline { 4 - 6 } & & MAPA & INCRA & CONAB \\
\hline $\begin{array}{l}\mathbf{( 0 )} \text { Incipiente } \\
\text { Ousência de definição de níveis } \\
\text { organizacionais na avaliação de } \\
\text { desempenho }\end{array}$ & $\begin{array}{l}\text { Não } \\
(0 \%)\end{array}$ & $\begin{array}{l}\text { Não } \\
(0 \%)\end{array}$ & $\begin{array}{l}\text { Não } \\
(0 \%)\end{array}$ \\
\hline $\begin{array}{l}\mathbf{( 1 )} \\
\text { Inicial }\end{array}$ & $\begin{array}{l}\text { Avaliação de desempenho dos } \\
\text { empregados e gerência da entidade }\end{array}$ & $\begin{array}{l}\text { Sim } \\
(100 \%)\end{array}$ & $\begin{array}{l}\text { Sim } \\
(100 \%)\end{array}$ & $\begin{array}{l}\text { Sim } \\
(100 \%)\end{array}$ \\
\hline $\begin{array}{l}\mathbf{( 2 )} \\
\text { Em formação }\end{array}$ & $\begin{array}{l}\text { Avaliação de desempenho da alta } \\
\text { gerência da entidade }\end{array}$ & $\begin{array}{l}\text { Parcial } \\
(50 \%)\end{array}$ & $\begin{array}{l}\text { Parcial } \\
(50 \%)\end{array}$ & $\begin{array}{l}\text { Não } \\
(0 \%)\end{array}$ \\
\hline $\begin{array}{l}\mathbf{( 3 )} \\
\text { Estabelecido }\end{array}$ & $\begin{array}{l}\text { Avaliação de desempenho da direção } \\
\text { executiva e corpo diretivo da entidade }\end{array}$ & $\begin{array}{l}\text { Não } \\
(0 \%)\end{array}$ & $\begin{array}{l}\text { Não } \\
(0 \%)\end{array}$ & $\begin{array}{l}\text { Não } \\
(0 \%)\end{array}$ \\
\hline
\end{tabular}

Fonte: procedimentos da pesquisa (2016).

O diagnóstico do nível de maturidade leva em consideração a média dos percentuais atribuídos a cada variável do ambiente de controle e a lógica implícita aos modelos de maturidade, de modo que o alcance de determinado estágio depende do cumprimento dos requisitos dos estágios anteriores. O esquema apresentado no quadro a seguir esclarece a lógica aplicada para o diagnóstico: 
Quadro 4 - Lógica de diagnóstico do nível de maturidade do ambiente de controle

\begin{tabular}{|l|l|}
\hline Nível & Características \\
\hline $\begin{array}{l}\text { (1) } \\
\text { Inicial }\end{array}$ & $\begin{array}{l}\text { A média dos percentuais das variáveis no nível de maturidade (1) foi igual } \\
\text { ou superior a 50\%. }\end{array}$ \\
\hline $\begin{array}{l}\text { (2) } \\
\text { Em formação }\end{array}$ & $\begin{array}{l}\text { A média dos percentuais das variáveis nos níveis de maturidade (1) e (2) } \\
\text { foi igual ou superior a 50\%. }\end{array}$ \\
\hline $\begin{array}{l}\text { (3) } \\
\text { Estabelecido }\end{array}$ & $\begin{array}{l}\text { A média dos percentuais das variáveis nos níveis de maturidade (1), (2) e } \\
\text { (3) foi igual ou superior a 50\%. }\end{array}$ \\
\hline $\begin{array}{l}\text { (0) } \\
\text { Incipiente }\end{array}$ & $\begin{array}{l}\text { O ambiente de controle não pôde ser classificado em nenhum dos demais } \\
\text { níveis de maturidade. }\end{array}$ \\
\hline
\end{tabular}

Fonte: procedimentos da pesquisa (2016).

Os procedimentos de análise documental e diagnóstico do nível de maturidade do ambiente de controle das entidades estudadas foram realizados no primeiro semestre de 2016.

\subsection{Limitações}

É importante destacar que o presente estudo possui limitações inerentes à técnica de pesquisa utilizada (análise documental). Há outras, relativas tanto à possibilidade de tais estruturas estarem em funcionamento, mas sem serem documentadas, quanto a estarem documentadas, porém sem estarem em funcionamento.

\section{ANÁLISE DOS RESULTADOS}

Esta seção apresenta e discute os resultados do ambiente de controle interno de forma comparada nas três organizações analisadas, levando em conta a composição de cada subdimensão do instrumento de pesquisa apresentado na seção anterior.

\subsection{Resultados da subdimensão Padrões de Conduta}

Podem-se definir padrões de conduta como todas as normas que estabelecem os parâmetros de integridade, ética, moral e valores esperados da conduta dos indivíduos da entidade. O COSO (2013b) afirma que o estabelecimento de padrões de conduta é uma característica relevante para demonstrar o comprometimento de uma organização com a integridade e valores éticos. 
O objetivo da primeira variável - Destinatários dos Padrões de Conduta - é identificar a existência de padrões de conduta próprios da entidade e a presença de disposições específicas para indivíduos ou grupos responsáveis por funções ou atividades significativas para os objetivos e riscos da entidade, inclusive terceiros relacionados. Os resultados são apresentados a seguir.

Quadro 5 - Diagnóstico da variável Destinatários dos Padrões de Conduta

\begin{tabular}{|c|c|c|c|c|}
\hline \multirow{2}{*}{ Nível } & \multirow{2}{*}{ Critério } & \multicolumn{3}{|c|}{ Entidades } \\
\hline & & MAPA & INCRA & CONAB \\
\hline $\begin{array}{l}\text { (0) } \\
\text { Incipiente }\end{array}$ & $\begin{array}{l}\text { Ausência de padrões de conduta próprios da } \\
\text { entidade }\end{array}$ & $\begin{array}{l}\text { Sim } \\
(100 \%)\end{array}$ & $\begin{array}{l}\text { Sim } \\
(100 \%)\end{array}$ & $\begin{array}{l}\text { Não } \\
(0 \%)\end{array}$ \\
\hline $\begin{array}{l}\text { (1) } \\
\text { Inicial }\end{array}$ & $\begin{array}{l}\text { A entidade possui padrões de conduta } \\
\text { próprios, com disposições gerais, aplicáveis } \\
\text { a todos os empregados }\end{array}$ & $\begin{array}{l}\text { Não } \\
(0 \%)\end{array}$ & $\begin{array}{l}\text { Não } \\
(0 \%)\end{array}$ & $\begin{array}{l}\text { Sim } \\
(100 \%)\end{array}$ \\
\hline $\begin{array}{l}\text { (2) } \\
\text { Em formação }\end{array}$ & $\begin{array}{l}\text { Padrões de conduta da entidade incluem } \\
\text { disposições específicas para gerentes, } \\
\text { indivíduos do corpo diretivo e empregados } \\
\text { de funções relevantes para a realização dos } \\
\text { objetivos da entidade }\end{array}$ & $\begin{array}{l}\text { Não } \\
(0 \%)\end{array}$ & $\begin{array}{l}\text { Não } \\
(0 \%)\end{array}$ & $\begin{array}{l}\text { Parcial } \\
(50 \%)\end{array}$ \\
\hline $\begin{array}{l}\text { (3) } \\
\text { Estabelecido }\end{array}$ & $\begin{array}{l}\text { Padrões de conduta da entidade incluem } \\
\text { disposições específicas para terceiros } \\
\text { (fornecedores de produtos e de serviços, bem } \\
\text { como empregados terceirizados que atuam } \\
\text { em nome da entidade), exigidas } \\
\text { contratualmente ou por SLA }\end{array}$ & $\begin{array}{l}\text { Não } \\
(0 \%)\end{array}$ & $\begin{array}{l}\text { Não } \\
(0 \%)\end{array}$ & $\begin{array}{l}\text { Não } \\
(0 \%)\end{array}$ \\
\hline
\end{tabular}

Fonte: elaborado pelos autores com base nos dados da pesquisa (2016).

O MAPA e o INCRA, sem códigos ou padrões de conduta próprios, seguem as seguintes disposições: Código de Ética Profissional do Servidor Público Civil do Poder Executivo Federal (Decreto $n^{\circ}$ 1.171/1994), Código de Conduta Ética dos Agentes Públicos em Exercício na Presidência e Vice-Presidência da República (Decreto no 4.081/2002) e resoluções da Comissão de Ética Pública. Tais normas são aplicáveis aos empregados de todas as entidades que integram a administração pública federal brasileira.

A CONAB, por sua vez, possui um código de ética próprio, que define princípios e diretrizes aplicáveis à atuação da empresa e seus colaboradores e dispõe sobre as atribuições e competências do comitê de ética da empresa. Os regulamentos de pessoal (NOC 10.105 e 10.106) incluem disposições sobre os deveres e proibições dos empregados, a responsabilidade civil, penal e administrativa dos empregados, o procedimento de notificação em caso de indisciplina ou insubordinação e as sanções aplicáveis. Nesse sentido, entende-se que a CONAB atende ao critério do nível de maturidade (1) Inicial. 
Os regulamentos de pessoal da CONAB definem deveres gerais para ocupantes de funções (comissionados). A CONAB possui também uma norma de governança corporativa (NOC 10.111), segundo a qual os conselheiros de administração e conselheiros fiscais devem agir exclusivamente no interesse da empresa, mantendo a objetividade e independência nos julgamentos, além de definir sua responsabilidade por danos resultantes de omissão no cumprimento de deveres e atos praticados com culpa ou dolo, ou com violação à lei ou ao estatuto social da empresa. Contudo, não inclui declaração explícita de deveres e proibições específicas para os conselheiros. Não foram identificadas declarações de deveres e proibições específicas para empregados de funções relevantes para cumprir os objetivos da empresa. Assim, entende-se que a CONAB atende parcialmente ao critério do nível de maturidade (2) Em formação.

O COSO (2013b) recomenda que os padrões de conduta reflitam o diagnóstico e a orientação estratégica das entidades, para a diferenciação em relação aos códigos de conduta genéricos. Assim, a edição de padrões de conduta próprios tende a reforçar a percepção dos empregados quanto ao comprometimento da entidade com a conduta ética, ao incluir previsões específicas para as peculiaridades dos ambientes interno e externo, além dos objetivos e riscos da entidade. Apenas a CONAB possui normas de conduta próprias, apesar de não estarem reunidas num código de conduta, o que pode dificultar a sua disseminação na organização.

O objetivo da segunda variável - Disseminação dos Padrões de Conduta, Ética e Valores - é verificar a inserção dos padrões de conduta da entidade e de temas ligados a ética e valores no programa de capacitação dos empregados, além da frequência e abrangência dos treinamentos realizados.

Quadro 6 - Diagnóstico da variável Disseminação dos Padrões de Conduta, Ética e Valores

\begin{tabular}{|l|l|l|l|l|}
\hline \multirow{2}{*}{ Nível } & Critério & \multicolumn{2}{|l|}{ Entidades } \\
\cline { 3 - 5 } & MAPA & INCRA & CONAB \\
\hline $\begin{array}{l}\text { (0) } \\
\text { Incipiente }\end{array}$ & $\begin{array}{l}\text { Ausência de ações de disseminação dos } \\
\text { padrões de conduta e temas ligados a ética e } \\
\text { valores na entidade }\end{array}$ & $\begin{array}{l}\text { Não } \\
(0 \%)\end{array}$ & $\begin{array}{l}\text { Sim } \\
(100 \%)\end{array}$ & $\begin{array}{l}\text { Sim } \\
(100 \%)\end{array}$ \\
\hline $\begin{array}{l}\mathbf{( 1 )} \\
\text { Inicial }\end{array}$ & $\begin{array}{l}\text { A entidade realiza ações de disseminação } \\
\text { dos padrões de conduta e temas ligados a } \\
\text { ética e valores }\end{array}$ & $\begin{array}{l}\text { Sim } \\
(100 \%)\end{array}$ & $\begin{array}{l}\text { Não } \\
(0 \%)\end{array}$ & $\begin{array}{l}\text { Não } \\
(0 \%)\end{array}$ \\
\hline
\end{tabular}


(CONTINUAÇÃO)

\begin{tabular}{|c|c|c|c|c|}
\hline $\begin{array}{l}\text { (2) } \\
\text { formação }\end{array}$ & $\begin{array}{l}\text { As ações para disseminar os padrões de } \\
\text { conduta da entidade e temas ligados a ética e } \\
\text { valores são programadas e incluem } \\
\text { treinamento presencial e ações de } \\
\text { sensibilização a distância por múltiplos } \\
\text { canais de comunicação }\end{array}$ & $\begin{array}{l}\text { Sim } \\
(100 \%)\end{array}$ & $\begin{array}{l}\text { Não } \\
(0 \%)\end{array}$ & $\begin{array}{l}\text { Não } \\
(0 \%)\end{array}$ \\
\hline $\begin{array}{l}\text { (3) } \\
\text { Estabelecido }\end{array}$ & $\begin{array}{l}\text { As ações de disseminação dos padrões de } \\
\text { conduta e temas ligados a ética e valores } \\
\text { incluem a sensibilização de terceirizados e } \\
\text { parceiros }\end{array}$ & $\begin{array}{l}\text { Não } \\
(0 \%)\end{array}$ & $\begin{array}{l}\text { Não } \\
(0 \%)\end{array}$ & $\begin{array}{l}\text { Não } \\
(0 \%)\end{array}$ \\
\hline
\end{tabular}

Fonte: elaborado pelos autores com base nos dados da pesquisa (2016).

O INCRA e a CONAB não apresentaram evidências de cumprimento dos critérios da variável. No MAPA, o Plano de Trabalho da Comissão de Ética para 2015 incluiu a "Ação Educativa", com as seguintes metas: "Realizar palestras e videoconferências abrangendo o maior número de Superintendências e unidades operacionais", "Capacitar multiplicadores para a realização das palestras e videoconferências" e "Primar pela conduta ética"; incluiu também a "Produção de material de divulgação", tendo a meta de "Divulgação periódica de princípios éticos" e as ações "Utilização do Intercom, abertura de tela e outros espaços de comunicação do MAPA para divulgação de princípios éticos", "Atualização da página da Ética no Portal do MAPA" e "Produção de cartilhas". Assim, entende-se que o MAPA atende ao critério do nível de maturidade (2) Em formação.

Definir uma estratégia de disseminação dos padrões de conduta é importante porque os empregados devem ter conhecimento das condutas consideradas aceitáveis segundo as expectativas da organização, bem como das condutas inaceitáveis e suas consequências (COSO, 2013b). Além disso, a disseminação das referências de conduta, ética e valores contribui para formar uma consciência de controle na organização (JOHNSTONE et al., 2012). Apenas o MAPA demonstrou ter planejado ações de disseminação de padrões de conduta, ética e valores. Cabe destacar a importância de que a disseminação seja constante, abrangente e planejada, utilizando-se de múltiplos meios de comunicação, de modo a atingir a maior quantidade possível de empregados, reforçando a percepção de que a entidade tem compromisso com a ética e valores.

O objetivo da terceira variável - Estrutura Organizacional para Avaliação da Aderência aos Padrões de Conduta - é verificar a existência da Comissão de Ética, as atividades por ela desempenhadas e a existência de política que determine a realização periódica de auditoria de ética pela auditoria interna ou auditor independente. 
Quadro 7 - Diagnóstico da variável Estrutura Organizacional para Avaliação da Aderência aos Padrões de Conduta

\begin{tabular}{|l|l|l|l|l|}
\hline \multirow{2}{*}{ Nível } & Critério & \multicolumn{3}{l|}{ Entidades } \\
\cline { 3 - 5 } $\begin{array}{l}\text { (0) } \\
\text { Incipiente }\end{array}$ & $\begin{array}{l}\text { Ausência de estrutura organizacional para } \\
\text { avaliar a aderência aos padrões de conduta } \\
\text { da entidade }\end{array}$ & $\begin{array}{l}\text { Não } \\
(0 \%)\end{array}$ & $\begin{array}{l}\text { Não } \\
(0 \%)\end{array}$ & Não (0\%) \\
\hline $\begin{array}{l}\mathbf{( 1 )} \\
\text { Inicial }\end{array}$ & $\begin{array}{l}\text { A entidade instituiu comissão de ética e } \\
\text { processo formal para avaliar a gestão da } \\
\text { ética na organização }\end{array}$ & $\begin{array}{l}\text { Parcial } \\
(50 \%)\end{array}$ & $\begin{array}{l}\text { Parcial } \\
(50 \%)\end{array}$ & $\begin{array}{l}\text { Sim } \\
(100 \%)\end{array}$ \\
\hline $\begin{array}{l}\mathbf{( 2 )} \\
\text { Em } \\
\text { formação }\end{array}$ & $\begin{array}{l}\text { A comissão de ética da entidade apura os } \\
\text { desvios de conduta e disponibiliza canal de } \\
\text { comunicação para denúncias anônimas }\end{array}$ & $\begin{array}{l}\text { Sim } \\
(100 \%)\end{array}$ & $\begin{array}{l}\text { Sim } \\
(100 \%)\end{array}$ & Não (0\%) \\
\hline $\begin{array}{l}\mathbf{( 3 )} \\
\text { Estabelecido }\end{array}$ & $\begin{array}{l}\text { Política de entidade determina a realização } \\
\text { periódica de auditoria de ética, conduzida } \\
\text { pela auditoria interna ou auditor } \\
\text { independente }\end{array}$ & $\begin{array}{l}\text { Não } \\
(0 \%)\end{array}$ & $\begin{array}{l}\text { Não } \\
(0 \%)\end{array}$ & Não (0\%) \\
\hline
\end{tabular}

Fonte: elaborado pelos autores com base nos dados da pesquisa (2016).

O MAPA possui comissão de ética formalmente instituída, porém não há evidências de tal comissão já ter avaliado a gestão da ética conforme processo coordenado pela CEP, nos termos do Decreto ${ }^{\circ}$ 6.029/2007, atendendo parcialmente ao critério do nível de maturidade (1) Inicial. A comissão de ética do MAPA planejou os trabalhos para o ano de 2015; segundo informa o Relatório de Atividades referente ao ano de 2014, as denúncias são apuradas nos termos do regimento interno da comissão, que prevê a possibilidade de denúncia anônima (art. 18, parágrafo único) e de rito processual em conformidade com a Resolução CEP no 10/2008 (Capítulo VI). Desse modo, considera-se que o MAPA atende ao critério do nível de maturidade (2) Em formação.

O INCRA possui comissão de ética, com regimento interno estabelecido pela Portaria n $586 / 2010$. Apesar disso, não foram apresentadas evidências de que a comissão de ética já tenha conduzido um processo de avaliação da gestão da ética conforme processo coordenado pela CEP, nos termos do Decreto $n^{\circ}$ 6.029/2007, atendendo parcialmente ao critério do nível de maturidade (1) Inicial. O regimento inclui normas gerais do procedimento e rito processual compatível com a Resolução CEP $n^{\circ}$ 10/2008 (Capítulo VII), prevê a possibilidade de denúncia anônima (art. 20, parágrafo único) e define entre os princípios fundamentais do trabalho desenvolvido pela comissão a proteção à identidade do denunciante (art. 31, inciso II). Assim, considera-se que o INCRA atende ao critério do nível de maturidade (2) Em formação. 
A CONAB também possui comissão de ética, instituída em seu regimento interno (competências definidas no art. 14), com titulares e suplentes designados nos termos da Portaria $n^{\circ} 549$, de 13/07/2015, e realizou em 2015 o processo de avaliação da gestão da ética conforme disposto no Decreto $\mathrm{n}^{\circ}$ 6.029/2007, atendendo ao critério do nível de maturidade (1) Inicial. A CONAB não apresentou evidências de atendimento aos critérios dos demais níveis de maturidade.

O International Federation of Accountants - IFAC (2001) recomenda designar um membro do corpo diretivo ou gerente sênior para investigar preocupações, relatadas confidencialmente, quanto aos padrões de conduta. É importante ainda "definir procedimentos claros para os empregados reportarem preocupações ou reclamações sobre má administração, violações da lei ou preocupações éticas, num ambiente em que serão apoiados e protegidos de represálias”iv (IFAC, 2001, p. 29). Nesse sentido, a existência de uma estrutura organizacional para avaliar a gestão da ética também contribui para a percepção de que a entidade tem compromisso com ética e valores.

Com base no diagnóstico realizado na subdimensão Padrões de conduta, a seguir apresentam-se as recomendações para aprimorar as estruturas de CI das entidades estudadas.

1) No caso em que os requisitos de ética e valores peculiares à natureza das atividades são contrariados pela conduta de empregados e gerentes que desempenham atividades com alto risco inerente e atividades relevantes para cumprir os objetivos da entidade, eis as recomendações: do MAPA e do INCRA, desenvolver um código de conduta próprio; da CONAB, aperfeiçoar o código de conduta, reunindo as disposições dos padrões de ética e valores num único documento;

2) Considerando que os empregados e terceirizados da entidade não incorporam à cultura organizacional as expectativas de ética e valores das partes interessadas, a recomendação do INCRA e da CONAB é elaborar e implantar um programa de disseminação dos padrões de conduta, ética e valores, utilizando múltiplos canais de comunicação, inclusive treinamento; recomendação MAPA, INCRA e CONAB: incluir - no programa de disseminação dos padrões de conduta, ética e valores da entidade - ações para sensibilizar a todos os empregados e terceiros relacionados;

3) Descumprimento de requisitos legais e regulamentares a respeito da gestão da ética na entidade. Recomendação: estabelecer políticas e processos para realização periódica de auditorias de ética pela auditoria interna ou auditor externo ou independente e estabelecer 
políticas e processos para a avaliação periódica da gestão da ética (Decreto $n^{\circ}$ 6.029/2007), o planejamento e acompanhamento de ações de melhoria da gestão da ética;

4) Por fim, na CONAB foi identificado o seguinte risco: violações aos padrões ou código de ética na entidade não são adequadamente investigadas e sancionadas. Recomendação: estabelecer formalmente os procedimentos de apuração de violações aos padrões de ética da entidade, regulamentando e definindo os canais de comunicação para apresentação de denúncias anônimas.

Os resultados da pesquisa de Bernardi (1994) apontam que a detecção de fraudes está diretamente alinhada às crenças e valores intrínsecos ao auditor. Contudo, para McNamee e Fleming (2007), quando diz respeito às ações a serem desenvolvidas por este no campo ético, há necessidade de se proceder de forma racional e com base em procedimentos objetivos. Com base no cenário observado nas organizações, identificaram-se disfunções capazes de comprometer o desenvolvimento de um ambiente de controle comprometido com a integridade e com valores éticos, a exemplo da ausência quer de um planejamento e acompanhamento de ações voltadas para melhorar a gestão da ética, quer de ações de disseminação dos padrões de conduta.

Uma das consequências desse cenário é o risco de não existir alinhamento entre os objetivos organizacionais e as ações dos empregados (SPIRA; PAGE, 2003; WANDERLEY; FONSECA; DE PAULA, 2015), colocando em risco a integridade das ações e das informações geradas internamente.

\subsection{Resultados da subdimensão Independência e Competência do Corpo Diretivo}

Segundo o COSO (2013b), o corpo diretivo da entidade deve ser independente da gerência e demonstrar habilidades e perícia relevantes no cumprimento de suas responsabilidades de supervisão. O GAO (2014) acrescenta que os membros do corpo diretivo devem entender os objetivos da entidade, os riscos relacionados e as expectativas das partes interessadas, além de possuir conhecimentos especializados para realizar críticas construtivas à gerência e para tomar decisões de supervisão adequadas.

O objetivo da quarta variável - Políticas de Investigação de Vida Pregressa para o Corpo Diretivo - é identificar a existência de políticas e processos relativos à independência e 
à competência de membros do corpo diretivo da entidade, a frequência de tais procedimentos, a supervisão deles e a divulgação dos resultados. Os resultados são apresentados a seguir.

Quadro 8 - Diagnóstico da variável Políticas de Investigação de Vida Pregressa para o Corpo Diretivo

\begin{tabular}{|c|c|c|c|c|}
\hline \multirow{2}{*}{ Nível } & \multirow{2}{*}{ Critério } & \multicolumn{3}{|c|}{ Entidades } \\
\hline & & MAPA & INCRA & CONAB \\
\hline $\begin{array}{l}(0) \\
\text { Incipiente }\end{array}$ & $\begin{array}{l}\text { Ausência de políticas de investigação de vida } \\
\text { pregressa para os indivíduos do corpo } \\
\text { diretivo da entidade }\end{array}$ & $\begin{array}{l}\text { Sim } \\
(100 \%)\end{array}$ & $\begin{array}{l}\text { Sim } \\
(100 \%)\end{array}$ & $\begin{array}{l}\text { Sim } \\
(100 \%)\end{array}$ \\
\hline $\begin{array}{l}\text { (1) } \\
\text { Inicial }\end{array}$ & $\begin{array}{l}\text { Políticas da entidade estabelecem } \\
\text { procedimentos de investigação de vida } \\
\text { pregressa como parte do processo de seleção } \\
\text { dos candidatos ao corpo diretivo }\end{array}$ & $\begin{array}{l}\text { Não } \\
(0 \%)\end{array}$ & $\begin{array}{l}\text { Não } \\
(0 \%)\end{array}$ & $\begin{array}{l}\text { Não } \\
(0 \%)\end{array}$ \\
\hline $\begin{array}{l}\text { (2) } \\
\text { Em formação }\end{array}$ & $\begin{array}{l}\text { Políticas da entidade estabelecem a } \\
\text { investigação periódica de vida pregressa para } \\
\text { confirmar a competência e independência } \\
\text { dos membros do corpo diretivo }\end{array}$ & $\begin{array}{l}\text { Não } \\
(0 \%)\end{array}$ & $\begin{array}{l}\text { Não } \\
(0 \%)\end{array}$ & $\begin{array}{l}\text { Não } \\
(0 \%)\end{array}$ \\
\hline $\begin{array}{l}\text { (3) } \\
\text { Estabelecido }\end{array}$ & $\begin{array}{l}\text { Políticas da entidade estabelecem que os } \\
\text { procedimentos de investigação de vida } \\
\text { pregressa sejam supervisionados por um } \\
\text { comitê de nominação independente ou firma } \\
\text { de contratação e que os resultados devem ser } \\
\text { divulgados }\end{array}$ & $\begin{array}{l}\text { Não } \\
(0 \%)\end{array}$ & $\begin{array}{l}\text { Não } \\
(0 \%)\end{array}$ & $\begin{array}{l}\text { Não } \\
(0 \%)\end{array}$ \\
\hline
\end{tabular}

Fonte: elaborado pelos autores com base nos dados da pesquisa (2016).

Nenhuma das entidades analisadas apresentou evidências de cumprir os critérios da variável.

A independência dos membros do corpo diretivo é importante para manter a objetividade nas avaliações e julgamentos que fazem parte das atividades de supervisão das ações da gerência para alcançar os objetivos da organização. Nesse sentido, o IFAC (2001) recomenda que as entidades do setor público estabeleçam mecanismos adequados para garantir que os membros do corpo diretivo e os empregados não sejam influenciados por preconceito, viés ou conflito de interesse. Esses mecanismos podem incluir a exigência de uma divulgação completa dos interesses, incluindo atividades profissionais e privadas, atividades políticas e negócios.

Cabe observar que o setor governamental comporta organizações com variadas estruturas de governança; muitas dessas organizações não possuem um órgão com as funções de supervisão de um corpo diretivo. Das entidades estudadas, apenas a CONAB possui um corpo diretivo, contudo não apresentou evidências da existência de políticas de investigação 
de vida pregressa e requisitos de competências para os membros do seu conselho de administração.

O objetivo da quinta variável - Requisitos de Competências do Corpo Diretivo - é verificar a existência de políticas que definam os requisitos de competência dos indivíduos integrantes do corpo diretivo da entidade, inclusive a exigência de indivíduos com conhecimentos especializados, e a existência de um programa de capacitação para manutenção das competências necessárias ao cumprimento das responsabilidades de supervisão.

Quadro 9 - Diagnóstico da variável Requisitos de Competências do Corpo Diretivo

\begin{tabular}{|c|c|c|c|c|}
\hline \multirow{2}{*}{ Nível } & \multirow{2}{*}{ Critério } & \multicolumn{3}{|c|}{ Entidades } \\
\hline & & MAPA & INCRA & CONAB \\
\hline $\begin{array}{l}\text { (0) } \\
\text { Incipiente }\end{array}$ & $\begin{array}{l}\text { Indefinição de requisitos de competências } \\
\text { para os integrantes do corpo diretivo da } \\
\text { entidade }\end{array}$ & $\begin{array}{l}\text { Sim } \\
(100 \%)\end{array}$ & $\begin{array}{l}\text { Sim } \\
(100 \%)\end{array}$ & $\begin{array}{l}\text { Sim } \\
(100 \%)\end{array}$ \\
\hline $\begin{array}{l}\text { (1) } \\
\text { Inicial }\end{array}$ & $\begin{array}{llll}\text { Definição de requisitos } & \text { gerais } & \text { de } \\
\text { competências, exigidos de } & \text { todos } & \text { os } \\
\text { integrantes do corpo diretivo } & & \\
\end{array}$ & $\begin{array}{l}\text { Não } \\
(0 \%)\end{array}$ & $\begin{array}{l}\text { Não } \\
(0 \%)\end{array}$ & $\begin{array}{l}\text { Não } \\
(0 \%)\end{array}$ \\
\hline $\begin{array}{l}\text { (2) } \\
\text { formação }\end{array}$ & $\begin{array}{l}\text { Exigência de indivíduos com conhecimentos } \\
\text { especializados no corpo diretivo da entidade, } \\
\text { de acordo com as necessidades de } \\
\text { supervisão }\end{array}$ & $\begin{array}{l}\text { Não } \\
(0 \%)\end{array}$ & $\begin{array}{l}\text { Não } \\
(0 \%)\end{array}$ & $\begin{array}{l}\text { Não } \\
(0 \%)\end{array}$ \\
\hline $\begin{array}{l}\text { (3) } \\
\text { Estabelecido }\end{array}$ & $\begin{array}{llr}\text { Exigência de que os integrantes do corpo } \\
\text { diretivo cumpram um programa de } \\
\text { capacitação para } \quad \text { manutenção } \\
\text { conhecimentos dos } \\
\text { responsabilidades de supervisão } \\
\end{array}$ & $\begin{array}{l}\text { Não } \\
(0 \%)\end{array}$ & $\begin{array}{l}\text { Não } \\
(0 \%)\end{array}$ & $\begin{array}{l}\text { Não } \\
(0 \%)\end{array}$ \\
\hline
\end{tabular}

Fonte: elaborado pelos autores com base nos dados da pesquisa (2016).

Nenhuma das entidades analisadas apresentou evidências de cumprimento dos critérios da variável.

A competência dos membros do corpo diretivo é necessária para questionar as ações da gerência para alcançar os objetivos da organização (COSO, 2013b). Jensen (1993) destaca ainda a importância de ter indivíduos com conhecimentos especializados no corpo diretivo da entidade, adequados às necessidades da supervisão. $O$ treinamento de indução e de sensibilização contínua podem contribuir para desenvolver e preservar as competências dos membros do corpo diretivo (IFAC, 2001). Desse modo, é relevante o estabelecimento de políticas no sentido de prover o corpo diretivo das entidades governamentais de membros com as competências adequadas para o cumprimento de suas responsabilidades de supervisão. 
O COSO (2013b) afirma que a composição do corpo diretivo deve levar em conta as competências necessárias para supervisionar, questionar e avaliar adequadamente a alta gerência, incluindo padrões de integridade e ética, liderança, pensamento crítico e solução de problemas, além de conhecimentos e habilidades especializados em assuntos como controle interno, mercado, finanças, leis e regulamentos, responsabilidade social e ambiental, incentivos e compensação e tecnologia e sistemas relevantes. Os integrantes do corpo diretivo devem receber treinamentos para manter a relevância e atualidade de suas capacidades.

Com base no diagnóstico realizado na subdimensão Independência e Competência do Corpo Diretivo, a seguir apresentam-se as recomendações para aprimorar as estruturas de CI das entidades estudadas: 1) designação e/ou manutenção de indivíduos sem a independência necessária ao cumprimento de suas responsabilidades de controle interno para o corpo diretivo da entidade. Recomendação: estabelecer políticas, processos e procedimentos para investigar vida pregressa dos indivíduos do corpo diretivo da entidade, incluindo a repetição periódica dos procedimentos para confirmação da independência, a supervisão dos procedimentos por partes independentes e a divulgação dos resultados da investigação de vida pregressa; 2) designação de indivíduos para o corpo diretivo da entidade sem competências adequadas para realizar as atribuições e cumprir as responsabilidades de controle interno. Recomendação: desenvolver os requisitos de competências para o corpo diretivo da entidade, incluindo competências gerais, esperadas de todos os integrantes, e competências especializadas, conforme as responsabilidades de supervisão e estabelecer políticas que exijam quantidade mínima de indivíduos com competências especializadas no corpo diretivo da entidade e o cumprimento de um programa de capacitação para manutenção de competências adequadas às responsabilidades de supervisão.

Os resultados apontam que as organizações passam a assumir um risco substancial ao designar indivíduos sem a devida competência para o cargo a ser ocupado ou sem a necessária investigação de sua vida pregressa. isso, aliado às falhas da subdimensão Comprometimento e Valores Éticos, indica um possível ambiente organizacional em que os objetivos organizacionais não sejam alcançados em virtude do não alinhamento de expectativas, oriundo de possíveis vieses ou conflitos de interesse (JENSEN, 1993; IFAC, 2001). Adicionalmente demonstra-se a necessidade de ampliar a discussão acerca da meritocracia na administração pública, em especial no Brasil, para que os cargos da alta administração pública sejam ocupados por pessoas que disponham das competências técnicas necessárias para o cargo, como afirma Bilhim (2012). 


\subsection{Resultados da subdimensão Responsabilidades de Controle Interno e Requisitos de Competências}

O COSO (2013b) afirma que as responsabilidades de CI geralmente constituem três linhas de defesa contra a falha na realização dos objetivos da entidade: gerência e equipes $\left(1^{\mathrm{a}}\right.$ linha), funções de suporte aos negócios ( $2^{a}$ linha $)$ e auditoria interna ( $3^{a}$ linha).

O objetivo da sexta variável - Responsabilidades de Controle Interno na Organização - é verificar a existência de definição de autoridades e responsabilidades de controle interno ao longo dos níveis organizacionais da entidade, desde a alta gerência até os empregados de departamentos ou funções relevantes para os objetivos e riscos da entidade, inclusive terceirizados. Os resultados são apresentados a seguir.

Quadro 10 - Diagnóstico da variável Responsabilidades de Controle Interno na Organização

\begin{tabular}{|c|c|c|c|c|}
\hline \multirow{2}{*}{ Nível } & \multirow{2}{*}{ Critério } & \multicolumn{3}{|c|}{ Entidades } \\
\hline & & МАРА & INCRA & CONAB \\
\hline $\begin{array}{l}(0) \\
\text { Incipiente }\end{array}$ & $\begin{array}{l}\text { Ausência de definição das autoridades e } \\
\text { responsabilidades de controle interno na } \\
\text { entidade }\end{array}$ & $\begin{array}{l}\text { Não } \\
(0 \%)\end{array}$ & $\begin{array}{l}\text { Não } \\
(0 \%)\end{array}$ & $\begin{array}{l}\text { Não } \\
(0 \%)\end{array}$ \\
\hline $\begin{array}{l}\text { (1) } \\
\text { Inicial }\end{array}$ & $\begin{array}{l}\text { Definição das autoridades } \\
\text { responsabilidades de controle interno para a } \\
\text { alta gerência e a auditoria interna da entidade }\end{array}$ & $\begin{array}{l}\operatorname{Sim} \\
(50 \%)\end{array}$ & $\begin{array}{l}\text { Sim } \\
(100 \%)\end{array}$ & $\begin{array}{l}\operatorname{Sim} \\
(100 \%)\end{array}$ \\
\hline $\begin{array}{l}\text { (2) } \\
\text { Em } \\
\text { formação }\end{array}$ & $\begin{array}{l}\text { Definição das autoridades } \\
\text { responsabilidades de controle interno para os } \\
\text { gerentes das divisões, unidades operacionais } \\
\text { e funções de suporte relevantes para a } \\
\text { realização dos objetivos da entidade }\end{array}$ & $\begin{array}{l}\text { Sim } \\
(100 \%)\end{array}$ & $\begin{array}{l}\text { Sim } \\
(100 \%)\end{array}$ & $\begin{array}{l}\text { Sim } \\
(100 \%)\end{array}$ \\
\hline $\begin{array}{l}\text { (3) } \\
\text { Estabelecido }\end{array}$ & 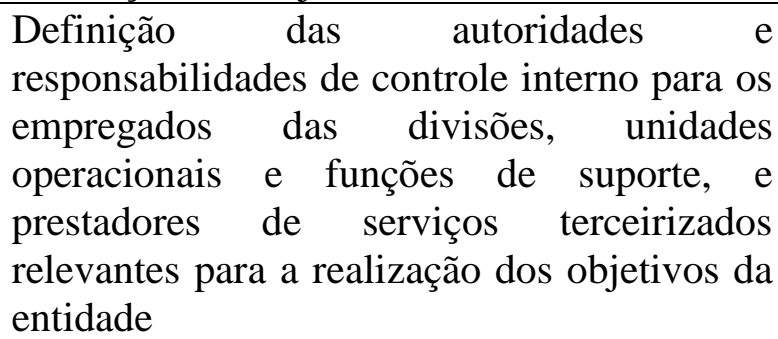 & $\begin{array}{l}\text { Não } \\
(0 \%)\end{array}$ & $\begin{array}{l}\text { Não } \\
(0 \%)\end{array}$ & $\begin{array}{l}\text { Sim } \\
(100 \%)\end{array}$ \\
\hline
\end{tabular}

Fonte: elaborado pelos autores com base nos dados da pesquisa (2016).

Os órgãos que integram a estrutura organizacional do MAPA possuem seus próprios regimentos internos, que definem autoridades e responsabilidades de controle para todos os níveis organizacionais, incluindo a alta gerência (secretários), a gerência (departamentos, coordenações-gerais, divisões, serviços e outros) e funções de suporte relevantes (coordenações-gerais de contabilidade, planejamento, orçamento e finanças, recursos humanos, logística e serviços gerais, tecnologia da informação e outras). O MAPA não possui 
Auditoria Interna. Assim, entende-se que o MAPA atende, parcialmente, ao critério do nível de maturidade (1) Inicial e, plenamente,e ao nível de maturidade (2) Em formação.

O INCRA possui Regimento Interno definindo autoridades e responsabilidades de controle para todos os níveis organizacionais, incluindo a alta gerência (presidente e diretores), a auditoria interna, a gerência (coordenações-gerais e divisões) e funções de suporte relevantes (coordenações-gerais de pessoas, administração e serviços gerais, orçamento e finanças, contabilidade, tecnologia e gestão da informação e outras). Nesse sentido, entende-se que o INCRA atende aos critérios dos níveis de maturidade (1) Inicial e (2) Em formação.

Quanto à CONAB, o Regimento Interno (NOC 10.104) define autoridades e responsabilidades de controle para todos os níveis organizacionais, incluindo a alta gerência (presidência, diretorias e superintendências), a auditoria interna, a gerência (gerências) e funções de suporte relevantes (superintendências de fiscalização de estoques, orçamento e finanças, contabilidade, administração, gestão da TI, informações do agronegócio e outras); além disso, o plano de cargos, carreiras e salários de 2009 define espaços ocupacionais, incluindo a descrição das principais atribuições, requisitos de formação e capacitação para os ocupantes, além das competências exigidas de cada espaço. Portanto, a CONAB atende integralmente a todos critérios dos níveis de maturidade de (1) Inicial a (3) Estabelecido.

Para que uma estrutura de CI funcione adequadamente, os empregados devem ter conhecimento de suas responsabilidades (COSO, 2013b). Nesse sentido, quanto mais claras e completas forem as atribuições de responsabilidades, maior a tendência de que os empregados atuem conforme as expectativas e contribuam para cumprir os objetivos da organização.

O objetivo da sétima variável - requisitos de competências na organização - é verificar a existência de definição de requisitos de competências ao longo dos níveis organizacionais da entidade, desde a alta gerência até os empregados de departamentos ou funções relevantes para os objetivos e riscos da entidade, inclusive terceirizados. 
Quadro 11 - Diagnóstico da variável Requisitos de Competências na Organização

\begin{tabular}{|c|c|c|c|c|}
\hline \multirow{2}{*}{ Nível } & \multirow{2}{*}{ Critério } & \multicolumn{3}{|c|}{ Entidades } \\
\hline & & MAPA & INCRA & CONAB \\
\hline $\begin{array}{l}\text { (0) } \\
\text { Incipiente }\end{array}$ & $\begin{array}{l}\text { Indefinição dos requisitos de competências } \\
\text { na entidade }\end{array}$ & $\begin{array}{l}\text { Sim } \\
(100 \%)\end{array}$ & $\begin{array}{l}\text { Sim } \\
(100 \%)\end{array}$ & $\begin{array}{l}\text { Não } \\
(0 \%)\end{array}$ \\
\hline $\begin{array}{l}\text { (1) } \\
\text { Inicial }\end{array}$ & $\begin{array}{lll}\text { Definição de requisitos gerais } & \text { de } \\
\text { competências, exigíveis de todos } & \text { os } \\
\text { empregados da entidade e prestadores } & \text { de } \\
\text { serviços terceirizados }\end{array}$ & $\begin{array}{l}\text { Não } \\
(0 \%)\end{array}$ & $\begin{array}{l}\text { Não } \\
(0 \%)\end{array}$ & $\begin{array}{l}\operatorname{Sim} \\
(100 \%)\end{array}$ \\
\hline $\begin{array}{l}\text { Em } \\
\text { formação }\end{array}$ & $\begin{array}{l}\text { Definição de requisitos de competências } \\
\text { específicos para empregados e gerentes das } \\
\text { divisões, unidades operacionais e funções de } \\
\text { suporte relevantes para a realização dos } \\
\text { objetivos da entidade, inclusive a auditoria } \\
\text { interna }\end{array}$ & $\begin{array}{l}\text { Não } \\
(0 \%)\end{array}$ & $\begin{array}{l}\text { Não } \\
(0 \%)\end{array}$ & $\begin{array}{l}\text { Sim } \\
(100 \%)\end{array}$ \\
\hline $\begin{array}{l}\text { (3) } \\
\text { Estabelecido }\end{array}$ & $\begin{array}{l}\text { Definição de requisitos de competências } \\
\text { específicos para a alta gerência da entidade }\end{array}$ & $\begin{array}{l}\text { Não } \\
(0 \%)\end{array}$ & $\begin{array}{l}\text { Não } \\
(0 \%)\end{array}$ & $\begin{array}{l}\text { Sim } \\
(100 \%)\end{array}$ \\
\hline
\end{tabular}

Fonte: elaborado pelos autores com base nos dados da pesquisa (2016).

O MAPA e o INCRA não apresentaram evidências de cumprimento dos critérios da variável. Na CONAB, o modelo de competências estabelecido no Plano de Cargos, Carreiras e Salários de 2009 inclui: competências estratégicas, que influenciam no desempenho do negócio e têm vínculo direto com a Estratégia da CONAB; competências técnicas, concentradas nos aspectos técnicos dos processos de trabalho e vinculadas aos espaços ocupacionais preenchidos pelos empregados ${ }^{\mathrm{v}}$; e competências de liderança, relacionadas com o papel esperado do líder na implementação da estratégia. As competências estratégicas e técnicas são exigíveis de todos os empregados da organização; as competências de liderança são aplicáveis aos empregados que ocupam função de chefia, em todos os níveis organizacionais. Desse modo, entende-se que a CONAB atende integralmente os critérios de todos os níveis de maturidade.

A falta de competência dos empregados para cumprir com suas atribuições é apontada por Johnstone et al. (2012) como uma das deficiências mais comuns no ambiente de controle das organizações. Para que os postos de trabalho possam ser providos de indivíduos com as competências adequadas, os requisitos de competências precisam ser definidos de forma clara e abrangente. Isso aumenta a tendência de que a estrutura de CI funcione conforme o esperado, contribuindo para alcançar os objetivos da organização.

Com base no diagnóstico realizado na subdimensão Responsabilidades de CI e Requisitos de Competências, a seguir apresentam-se as recomendações para o aprimoramento das estruturas de CI das entidades MAPA e INCRA. 1) No caso de atuação dos empregados e 
terceirizados que desempenham atividades relevantes para atingir os objetivos da entidade, mas sem que tais atividades apoiem o funcionamento adequado e necessário na estrutura de CI, eis a recomendação: definir as autoridades e responsabilidades de CI dos empregados e terceiros que desempenhem atividades relevantes para cumprir os objetivos da entidade. 2) Designação de indivíduos para a alta gerência da entidade, bem como empregados, que não possuam competências adequadas para a realização de suas atribuições e o cumprimento de suas responsabilidades de CI. Recomendação: desenvolver os requisitos de competências da entidade, incluindo requisitos gerais para todos os empregados e terceiros, requisitos específicos para empregados e gerentes que desempenham atividades relevantes para cumprir os objetivos da entidade, e requisitos específicos para a alta gerência.

O resultado dessa subdimensão traduz a consequência do que se identificou na subdimensão Independência e Competência do Corpo Diretivo, dado que, nela, a avaliação da maturidade apontou a ausência de independência necessária do corpo diretivo ao cumprimento de suas responsabilidades de controle interno, passando a permear a organização como um todo, fazendo com que nessa subdimensão se identifique o cenário ora observado, de ausência de requisitos específicos a empregados e gerentes. Com isso, há um risco adicional de que os objetivos pessoais não sejam convergentes com os da organização, ampliando-se o risco e a possibilidade de desvios de conduta e/ou de fraude (FADZIL; HARON; JANTAN, 2005; SPIRA; PAGE, 2003).

\subsection{Resultados da subdimensão Atração, Desenvolvimento e Retenção de Indivíduos}

O COSO (2013b) afirma que o comprometimento com a competência é apoiado e está embutido nos processos de gerenciamento de recursos humanos para a atração, desenvolvimento, avaliação e retenção de pessoal adequado, inclusive terceirizados.

O objetivo da oitava variável - Programa de Desenvolvimento de Competências - é verificar a existência de um programa de desenvolvimento de competências para os empregados da entidade, e as características do programa. 
Quadro 12 - Diagnóstico da variável Programa de Desenvolvimento de Competências

\begin{tabular}{|c|c|c|c|c|}
\hline \multirow{2}{*}{ Nível } & \multirow{2}{*}{ Critério } & \multicolumn{3}{|c|}{ Entidades } \\
\hline & & MAPA & INCRA & CONAB \\
\hline $\begin{array}{l}\text { (0) } \\
\text { Incipiente }\end{array}$ & $\begin{array}{l}\text { Ausência de programa de desenvolvimento } \\
\text { de competências para os empregados da } \\
\text { entidade }\end{array}$ & $\begin{array}{l}\text { Não } \\
(0 \%)\end{array}$ & $\begin{array}{l}\text { Não } \\
(0 \%)\end{array}$ & $\begin{array}{l}\text { Não } \\
(0 \%)\end{array}$ \\
\hline $\begin{array}{l}\text { (1) } \\
\text { Inicial }\end{array}$ & $\begin{array}{l}\text { A entidade possui um programa de } \\
\text { desenvolvimento de competências }\end{array}$ & $\begin{array}{l}\text { Sim } \\
(100 \%)\end{array}$ & \begin{tabular}{|l|} 
Sim \\
$(100 \%)$
\end{tabular} & $\begin{array}{l}\text { Sim } \\
(100 \%)\end{array}$ \\
\hline $\begin{array}{l}\text { (2) } \\
\text { formação }\end{array}$ & $\begin{array}{l}\text { O programa de desenvolvimento } \\
\text { competências abrange as funções } \\
\text { atividades relevantes para realizar } \\
\begin{array}{l}\text { objetivos da entidade } \\
\text { objos }\end{array}\end{array}$ & $\begin{array}{l}\text { Sim } \\
(100 \%)\end{array}$ & $\begin{array}{l}\text { Sim } \\
(100 \%)\end{array}$ & $\begin{array}{l}\text { Sim } \\
(100 \%)\end{array}$ \\
\hline $\begin{array}{l}\text { (3) } \\
\text { Estabelecido }\end{array}$ & $\begin{array}{l}\text { O programa de desenvolvimento de } \\
\text { competências da entidade inclui múltiplas } \\
\text { técnicas de entrega (ações instrucionais em } \\
\text { sala de aula, autoestudo e treinamento no } \\
\text { trabalho) }\end{array}$ & $\begin{array}{l}\text { Sim } \\
(100 \%)\end{array}$ & $\begin{array}{l}\text { Sim } \\
(100 \%)\end{array}$ & $\begin{array}{l}\text { Sim } \\
(100 \%)\end{array}$ \\
\hline
\end{tabular}

Fonte: elaborado pelos autores com base nos dados da pesquisa (2016).

No âmbito do MAPA, a Portaria $n^{\circ}$ 482/2012 dispõe sobre ações de educação continuada na entidade, definindo que as ações devem ter como diretrizes a vinculação com os objetivos e estratégias institucionais e o desenvolvimento de competências críticas para a organização (art. $5^{\circ}$, incisos I e XI). Os eventos de capacitação podem ser presenciais ou à distância, incluída a aprendizagem em serviço (art. $6^{\circ}$, inciso V). No INCRA, a Instrução Normativa n ${ }^{\circ}$ 78/2014 regulamenta a participação dos servidores da entidade em eventos de capacitação, com o objetivo de assegurar a formação e o aperfeiçoamento das competências necessárias ao desenvolvimento das atividades institucionais do INCRA (art. $2^{\circ}$ ), definindo ainda que as ações de capacitação deverão observar o desenvolvimento das competências institucionais conforme as prioridades definidas pelo Comitê Gestor de Capacitação e o custobenefício da ação de capacitação (art. $5^{\circ}$, incisos II e III) e que as atividades de capacitação podem ocorrer nas modalidades presencial, semipresencial e a distância (art. $7^{\circ}$, inciso III), incluído o treinamento em serviço (art. $3^{\circ}$, inciso IV).

Na CONAB, a Norma de Treinamento, Desenvolvimento e Educação de Recursos Humanos (NOC 60.103) define que as ações de capacitação devem ser definidas pela companhia para atender à missão, aos objetivos e às metas estabelecidos pelo Planejamento Estratégico e estruturados em programas delineados em função das características das ações de treinamento e da natureza das atividades da companhia, incluindo ações de capacitação internas, externas, a distância e particulares. 
Desse modo, entende-se que MAPA, INCRA e CONAB atendem aos critérios dos níveis de maturidade (1) Inicial, (2) Em formação e (3) Estabelecido.

A manutenção de um corpo funcional qualificado é importante para a realização dos objetivos de uma organização (COSO, 2013b). O IFAC (2001) destaca ainda a relevância dos programas de treinamento como mecanismo de retenção de pessoal competente. Nesse sentido, elaborar mecanismos para a atração, desenvolvimento e retenção de indivíduos competentes aumenta a chance de que a organização alcance seus objetivos.

Para tanto, verifica-se em todas entidades a existência de programas para desenvolver as competências de seus empregados, incluindo o desenvolvimento de competências críticas para a entidade e múltiplos meios de realização das ações de retenção. As características diagnosticadas nessa subdimensão com a aplicação do modelo de maturidade aqui desenvolvido não ensejaram a identificação de riscos e proposta de recomendações para as entidades estudadas.

\subsection{Resultados da subdimensão Avaliação de Desempenho}

O GAO (2014) afirma que a avaliação de desempenho é um dos recursos utilizados pela gerência para promover o accountability do pessoal da entidade por suas responsabilidades de controle interno. Para tanto, o COSO (2013b) destaca a necessidade de avaliar a aderência aos padrões de conduta e níveis esperados de competência, além do desempenho dos indivíduos na realização dos objetivos e metas definidos em todos os níveis da organização.

O objetivo da nona variável - fatores da avaliação de desempenho - é identificar os aspectos analisados no processo de avaliação de desempenho da entidade (produtividade, conduta ética e competências).

Quadro 13 - Diagnóstico da variável Fatores da Avaliação de Desempenho

\begin{tabular}{|c|c|c|c|c|}
\hline \multirow{2}{*}{ Nível } & \multirow{2}{*}{ Critério } & \multicolumn{3}{|c|}{ Entidades } \\
\hline & & MAPA & INCRA & CONAB \\
\hline $\begin{array}{l}\text { (0) } \\
\text { Incipiente }\end{array}$ & $\begin{array}{l}\text { Ausência de definição de fatores de } \\
\text { avaliação de desempenho }\end{array}$ & $\begin{array}{l}\text { Não } \\
(0 \%)\end{array}$ & $\begin{array}{l}\text { Não } \\
(0 \%)\end{array}$ & $\begin{array}{l}\text { Não } \\
(0 \%)\end{array}$ \\
\hline $\begin{array}{l}\text { (1) } \\
\text { Inicial }\end{array}$ & $\begin{array}{l}\text { Avaliação da produtividade dos } \\
\text { empregados da entidade }\end{array}$ & $\begin{array}{l}\text { Sim } \\
(100 \%)\end{array}$ & $\begin{array}{l}\text { Sim } \\
(100 \%)\end{array}$ & $\begin{array}{l}\text { Sim } \\
(100 \%)\end{array}$ \\
\hline
\end{tabular}


(CONTINUAÇÃO)

\begin{tabular}{|l|ll|l|l|l|}
\hline $\begin{array}{l}\text { (2) } \\
\text { Em formação }\end{array}$ & $\begin{array}{l}\text { Avaliação da conduta ética dos } \\
\text { empregados da entidade }\end{array}$ & $\begin{array}{l}\text { Sim } \\
(100 \%)\end{array}$ & $\begin{array}{l}\text { Sim } \\
(100 \%)\end{array}$ & $\begin{array}{l}\text { Não } \\
(0 \%)\end{array}$ \\
\hline $\begin{array}{l}\text { (3) } \\
\text { Estabelecido }\end{array}$ & $\begin{array}{l}\text { Avaliação das competências } \\
\text { empregados da entidade }\end{array}$ & $\begin{array}{l}\text { Sim } \\
(100 \%)\end{array}$ & $\begin{array}{l}\text { Sim } \\
(100 \%)\end{array}$ & $\begin{array}{l}\text { Sim } \\
(100 \%)\end{array}$ \\
\hline
\end{tabular}

Fonte: elaborado pelos autores com base nos dados da pesquisa (2016).

A avaliação de desempenho individual dos servidores do MAPA baseia-se em fatores de competência, conforme o art. 17, inciso III da Portaria MAPA n ${ }^{\circ}$ 499/2012. Os fatores de competência avaliados são: produtividade e qualidade no trabalho; conhecimento de métodos e técnicas; trabalho em equipe; comprometimento com o trabalho; ética e disciplina; autodesenvolvimento; capacidade de iniciativa; relacionamento interpessoal; e flexibilidade a mudanças.

Os fatores de avaliação de desempenho individual dos servidores do INCRA, nos termos do art. 13 da Portaria MDA n 26/2012, são: produtividade e qualidade no trabalho; conhecimento de métodos e técnicas; trabalho em equipe; comprometimento com o trabalho; e cumprimento das normas de procedimento e de conduta. Nesse sentido, o MAPA e o INCRA atendem aos critérios dos níveis de maturidade (1) Inicial, (2) Em formação e (3) Estabelecido.

A Política de Gestão do Desempenho da CONAB informa no item "8.3 Critérios de Avaliação" que a avaliação é realizada tendo como critério o desempenho dos empregados em “Competências Estratégicas" (1. Trabalho em Equipe, 2. Adaptação à Mudança, 3. Iniciativa e dinamismo, 4. Conhecimento da Organização, 5. Aquisição e Transferência de Conhecimentos e 6. Foco no Cliente). Os gestores da entidade são avaliados também considerando seu desempenho em "Competências de Liderança" (1. Gestão Estratégica, 2. Orientação para Resultados, 3. Gestão de Processos, 4. Liderança e Gestão de Equipes e 5. Negociação). Nesse sentido, entende-se que a avaliação de desempenho da CONAB inclui critérios para avaliar a produtividade e as competências de seus empregados, mas tal avaliação não possui critérios relacionados à conduta ética dos empregados, de modo que a CONAB atende aos critérios dos níveis de maturidade (1) Inicial e (3) Estabelecido.

A avaliação de desempenho é um mecanismo importante para estimular o cumprimento das responsabilidades de CI por parte dos empregados da organização (COSO, 2013b). Nesse sentido, é um elemento relevante para estabelecer um ambiente de controle favorável ao funcionamento da estrutura de CI, contribuindo para realizar os objetivos da organização. Johnstone et al. (2012) relacionam a falta de cobrança de um comportamento 
ético e a falta de competência do pessoal para a realização de suas atribuições entre as deficiências mais comuns no ambiente de controle das organizações. Assim, é importante também que a avaliação de desempenho inclua entre seus fatores a conduta ética e a manutenção das competências necessárias.

O objetivo da décima variável - Níveis Organizacionais da Avaliação de Desempenho - é identificar os aspectos analisados no processo de avaliação de desempenho da entidade (produtividade, conduta ética e competências).

Quadro 14 - Diagnóstico da variável Níveis Organizacionais da Avaliação de Desempenho

\begin{tabular}{|l|l|l|l|l|}
\hline \multirow{2}{*}{ Nível } & Critério & \multicolumn{4}{l|}{ Entidades } \\
\cline { 3 - 6 } & MAPA & INCRA & CONAB \\
\hline $\begin{array}{l}\text { (0) } \\
\text { Incipiente }\end{array}$ & $\begin{array}{l}\text { Ausência de definição de níveis } \\
\text { organizacionais na avaliação de } \\
\text { desempenho }\end{array}$ & $\begin{array}{l}\text { Não } \\
(0 \%)\end{array}$ & $\begin{array}{l}\text { Não } \\
(0 \%)\end{array}$ & $\begin{array}{l}\text { Não } \\
(0 \%)\end{array}$ \\
\hline $\begin{array}{l}\mathbf{1}) \\
\text { Inicial }\end{array}$ & $\begin{array}{l}\text { Avaliação de desempenho dos } \\
\text { empregados e gerência da entidade }\end{array}$ & $\begin{array}{l}\text { Sim } \\
(100 \%)\end{array}$ & $\begin{array}{l}\text { Sim } \\
(100 \%)\end{array}$ & $\begin{array}{l}\text { Sim } \\
(100 \%)\end{array}$ \\
\hline $\begin{array}{l}\mathbf{( 2 )} \\
\text { Em formação }\end{array}$ & $\begin{array}{l}\text { Avaliação de desempenho da alta } \\
\text { gerência da entidade }\end{array}$ & $\begin{array}{l}\text { Parcial } \\
(50 \%)\end{array}$ & $\begin{array}{l}\text { Parcial } \\
(50 \%)\end{array}$ & $\begin{array}{l}\text { Não } \\
(0 \%)\end{array}$ \\
\hline $\begin{array}{l}\mathbf{( 3 )} \\
\text { Estabelecido }\end{array}$ & $\begin{array}{l}\text { Avaliação de desempenho da direção } \\
\text { executiva e corpo diretivo da entidade }\end{array}$ & $\begin{array}{l}\text { Não } \\
(0 \%)\end{array}$ & $\begin{array}{l}\text { Não } \\
(0 \%)\end{array}$ & $\begin{array}{l}\text { Não } \\
(0 \%)\end{array}$ \\
\hline
\end{tabular}

Fonte: elaborado pelos autores com base nos dados da pesquisa (2016).

A avaliação de desempenho dos servidores do MAPA (Portaria MAPA n 499/2012) e do INCRA (Portaria MDA n 26/2012) não ocupantes de cargo em comissão e dos servidores ocupantes de cargos DAS 1, 2 e 3 leva em consideração o desempenho institucional (cumprimento de metas globais e intermediárias) e o desempenho individual (pontuação atribuída pela chefia imediata, pares e pelo próprio servidor a fatores de produtividade, conhecimento, colaboração, comprometimento e comportamento do servidor). Os ocupantes de cargos DAS 4, 5 e 6 são avaliados com base apenas no desempenho institucional.

A Política de Gestão do Desempenho da CONAB orienta o processo de avaliação de desempenho de empregados e gestores. O gestor é definido como “o empregado responsável pela gestão técnico-administrativa de determinadas áreas da Companhia, liderando as respectivas equipes de trabalho sob sua hierarquia, percebendo, para tanto, gratificação de função de confiança". O Relatório Anual de Auditoria de Contas da CONAB, do exercício de 2014, informa que a CONAB ainda não havia implantado a avaliação formal de desempenho da Diretoria e do Conselho de Administração. 
Desse modo, entende-se que as três entidades atendem integralmente ao critério do nível de maturidade (1) Inicial. O MAPA e o INCRA atendem parcialmente ao critério do nível de maturidade (2) Em formação.

Considerando que a avaliação de desempenho é fator de alinhamento da atuação dos empregados com as expectativas da organização, é necessário que ela seja abrangente, incluindo a alta gerência e a direção executiva, que definem as diretrizes para o trabalho dos empregados dos demais níveis da organização e estabelecem o ambiente de controle pelo exemplo de suas atitudes (COSO, 2013b). A ausência da alta gerência e direção executiva na avaliação de desempenho resulta na ausência de feedback, prejudicando sua atuação na realização dos objetivos da entidade, e pode transmitir uma ideia de ausência de compromisso dos níveis organizacionais superiores com a ética e valores, prejudicando o ambiente de controle.

O objetivo da décima primeira variável - níveis organizacionais das metas de desempenho - é identificar os níveis organizacionais da entidade para os quais são estabelecidas metas de desempenho, desde aquelas no nível da entidade até as individuais, para cada empregado.

Quadro 15 - Diagnóstico da variável Níveis Organizacionais das Metas de Desempenho

\begin{tabular}{|c|c|c|c|c|}
\hline \multirow{2}{*}{ Nível } & \multirow{2}{*}{ Critério } & \multicolumn{3}{|c|}{ Entidades } \\
\hline & & MAPA & INCRA & CONAB \\
\hline $\begin{array}{l}\text { (0) } \\
\text { Incipiente }\end{array}$ & $\begin{array}{lccr}\begin{array}{l}\text { Ausência de } \\
\text { organizacionais }\end{array} & \text { definição } & \text { de } & \text { níveis } \\
\text { desempenho } & & \text { metas } & \text { de } \\
\end{array}$ & $\begin{array}{l}\text { Não } \\
(0 \%)\end{array}$ & $\begin{array}{l}\text { Não } \\
(0 \%)\end{array}$ & $\begin{array}{l}\text { Sim } \\
(100 \%)\end{array}$ \\
\hline $\begin{array}{l}\text { (1) } \\
\text { Inicial }\end{array}$ & $\begin{array}{l}\text { Definição de metas de desempenho em } \\
\text { nível de entidade }\end{array}$ & $\begin{array}{l}\text { Sim } \\
(100 \%)\end{array}$ & $\begin{array}{l}\text { Sim } \\
(100 \%)\end{array}$ & $\begin{array}{l}\text { Não } \\
(0 \%)\end{array}$ \\
\hline $\begin{array}{l}\text { (2) } \\
\text { Em } \\
\text { formação }\end{array}$ & $\begin{array}{l}\text { Definição de metas de desempenho para } \\
\text { as unidades e subunidades } \\
\text { organizacionais da entidade }\end{array}$ & $\begin{array}{l}\text { Sim } \\
(100 \%)\end{array}$ & $\begin{array}{l}\text { Sim } \\
(100 \%)\end{array}$ & $\begin{array}{l}\text { Não } \\
(0 \%)\end{array}$ \\
\hline $\begin{array}{l}\text { (3) } \\
\text { Estabelecido }\end{array}$ & $\begin{array}{l}\text { Definição de metas de desempenho } \\
\text { individuais, para cada empregado da } \\
\text { entidade }\end{array}$ & $\begin{array}{l}\text { Sim } \\
(100 \%)\end{array}$ & $\begin{array}{l}\text { Sim } \\
(100 \%)\end{array}$ & $\begin{array}{l}\text { Não } \\
(0 \%)\end{array}$ \\
\hline
\end{tabular}

Fonte: elaborado pelos autores com base nos dados da pesquisa (2016).

No âmbito do MAPA (Portaria MAPA n 499/2012) e do INCRA (Portaria MDA nº 26/2012), a avaliação de desempenho institucional é segmentada em metas globais (aplicáveis ao ente como um todo, fixadas levando em consideração o Planejamento Estratégico, o Plano Plurianual, a Lei de Diretrizes Orçamentárias e a Lei Orçamentária) e metas intermediárias (estabelecidas no plano de trabalho de cada unidade de avaliação). Além disso, os planos de 
trabalho incluem as metas de desempenho individual (pactuadas entre o servidor e a respectiva chefia, em consonância com as demais metas). Desse modo, ambos atendem aos critérios dos níveis de maturidade (1) Inicial e (2) Em formação. A CONAB não apresentou evidências de cumprimento dos critérios da variável.

A definição de metas é importante para que os empregados da organização avaliem seu próprio desempenho e ajustem o seu comportamento conforme necessário para atender às expectativas da organização. Assim, é importante que as metas sejam definidas não apenas em nível de entidade, mas também para cada empregado da organização.

O objetivo da décima segunda variável - Recompensas e Sanções da Avaliação de Desempenho - é identificar a frequência com a qual a entidade realiza o processo de avaliação de desempenho.

Quadro 16 - Diagnóstico da variável Recompensas e Sanções da Avaliação de Desempenho

\begin{tabular}{|l|l|l|l|l|}
\hline \multirow{2}{*}{ Nível } & Critério & \multicolumn{5}{l|}{ Entidades } \\
\cline { 3 - 5 } & MAPA & INCRA & CONAB \\
\hline $\begin{array}{l}\text { In) } \\
\text { Incipiente }\end{array}$ & $\begin{array}{l}\text { Ausência de definição de recompensas e } \\
\text { sanções na avaliação de desempenho }\end{array}$ & $\begin{array}{l}\text { Não } \\
(0 \%)\end{array}$ & $\begin{array}{l}\text { Não } \\
(0 \%)\end{array}$ & $\begin{array}{l}\text { Não } \\
(0 \%)\end{array}$ \\
\hline $\begin{array}{l}(\mathbf{1}) \\
\text { Inicial }\end{array}$ & $\begin{array}{l}\text { Recompensas e sanções de caráter } \\
\text { administrativo e disciplinar }\end{array}$ & $\begin{array}{l}\text { Sim } \\
(100 \%)\end{array}$ & $\begin{array}{l}\text { Não } \\
(0 \%)\end{array}$ & $\begin{array}{l}\text { Sim } \\
(100 \%)\end{array}$ \\
\hline $\begin{array}{l}\mathbf{( 2 )} \\
\text { Em } \\
\text { formação }\end{array}$ & $\begin{array}{l}\text { Parcela variável da remuneração dos } \\
\text { empregados é afetada }\end{array}$ & $\begin{array}{l}\text { Sim } \\
(100 \%)\end{array}$ & $\begin{array}{l}\text { Sim } \\
(100 \%)\end{array}$ & $\begin{array}{l}\text { Não } \\
(0 \%)\end{array}$ \\
\hline $\begin{array}{l}(3) \\
\text { Estabelecido }\end{array}$ & $\begin{array}{l}\text { Promoção (evolução nos níveis da } \\
\text { carreira) e movimentação (inclusive } \\
\text { remoção) levam em consideração as } \\
\text { avaliações de desempenho do empregado }\end{array}$ & $\begin{array}{l}\text { Parcial } \\
(50 \%)\end{array}$ & $\begin{array}{l}\text { Parcial } \\
(50 \%)\end{array}$ & $\begin{array}{l}\text { Parcial } \\
(50 \%)\end{array}$ \\
\hline
\end{tabular}

Fonte: elaborado pelos autores com base nos dados da pesquisa (2016).

A Portaria MAPA n 499/2012 regula os critérios e procedimentos para a avaliação de desempenho destinada a conceder as gratificações dos servidores do MAPA. Além disso, conforme dispõe a portaria, em seu art. 25, os servidores que obtiverem avaliação de desempenho individual inferior a cinquenta por cento da pontuação máxima prevista serão submetidos a processo de capacitação ou de análise da adequação funcional. Nesse sentido, o MAPA cumpre os critérios dos níveis de maturidade (1) Inicial e (2) Em formação.

O INCRA não apresentou evidência de cumprimento do critério do nível (1) Inicial. Contudo, a Portaria MDA nº 26/2012 regula os critérios e procedimentos para a avaliação de desempenho para fins de concessão das gratificações dos servidores do INCRA, atendendo ao critério do nível de maturidade (2) Em formação. 
A Lei $n^{\circ}$ 11.090/2005, que dispõe sobre os planos de carreira de servidores do MAPA e do INCRA, define que o desenvolvimento na carreira (progressão funcional e promoção) deve observar a avaliação de desempenho. Apesar disso, não foram identificadas evidências de que os processos de movimentação dos servidores de MAPA e INCRA tenham de observar a avaliação de desempenho. Assim, ambos atendem parcialmente ao critério do nível de maturidade (3) Estabelecido.

A Política de Gestão do Desempenho da CONAB informa no item "9.2 Treinamento e Desenvolvimento" que os empregados que apresentarem desempenho mediano ou inferior deverão cumprir as horas de treinamento definidas pela GECAP para o desenvolvimento de cada competência. Ainda, a Política informa no item "8.5 Promoção por Mérito" que a nota final inferior a 70 na avaliação de desempenho torna o empregado inelegível ao processo de promoção por mérito. Assim, entende-se que a CONAB cumpre integralmente o critério do nível de maturidade (1) Inicial e parcialmente o critério do nível de maturidade (3) Estabelecido.

Para que surta o efeito esperado sobre a conduta dos empregados, a avaliação de desempenho deve estar ligada a um sistema de incentivos e recompensas (COSO, 2013b). Os empregados devem ter conhecimento dos benefícios que não lhes serão facultados e das sanções a que estarão sujeitos em caso de desempenho repetidamente abaixo das expectativas da entidade, e tais benefícios e sanções devem ser relevantes o suficiente para influenciar a conduta dos empregados.

Quadro 17 - Diagnóstico da variável Frequência da Avaliação de Desempenho

\begin{tabular}{|l|l|l|l|l|}
\hline \multirow{2}{*}{ Nível } & Critério & \multicolumn{3}{l|}{ Entidades } \\
\cline { 3 - 5 } & & MAPA & INCRA & CONAB \\
\hline $\begin{array}{l}\text { In) } \\
\text { Incipiente }\end{array}$ & $\begin{array}{l}\text { Ausência de definição da frequência da } \\
\text { avaliação de desempenho }\end{array}$ & $\begin{array}{l}\text { Não } \\
(0 \%)\end{array}$ & $\begin{array}{l}\text { Não } \\
(0 \%)\end{array}$ & $\begin{array}{l}\text { Não } \\
(0 \%)\end{array}$ \\
\hline $\begin{array}{l}\mathbf{( 1 )} \\
\text { Inicial }\end{array}$ & $\begin{array}{l}\text { Avaliação de desempenho realizada } \\
\text { anualmente }\end{array}$ & $\begin{array}{l}\text { Sim } \\
(100 \%)\end{array}$ & $\begin{array}{l}\text { Sim } \\
(100 \%)\end{array}$ & $\begin{array}{l}\text { Sim } \\
(100 \%)\end{array}$ \\
\hline $\begin{array}{l}\mathbf{( 2 )} \\
\text { Em } \\
\text { formação }\end{array}$ & $\begin{array}{l}\text { Avaliação de desempenho realizada } \\
\text { semestralmente }\end{array}$ & $\begin{array}{l}\text { Não } \\
(0 \%)\end{array}$ & $\begin{array}{l}\text { Não } \\
(0 \%)\end{array}$ & $\begin{array}{l}\text { Não } \\
(0 \%)\end{array}$ \\
\hline $\begin{array}{l}(3) \\
\text { Estabelecido }\end{array}$ & $\begin{array}{l}\text { Avaliação de desempenho realizada } \\
\text { quadrimestralmente (ou com frequência } \\
\text { maior) }\end{array}$ & $\begin{array}{l}\text { Não } \\
(0 \%)\end{array}$ & $\begin{array}{l}\text { Não } \\
(0 \%)\end{array}$ & $\begin{array}{l}\text { Não } \\
(0 \%)\end{array}$ \\
\hline
\end{tabular}

Fonte: elaborado pelos autores com base nos dados da pesquisa (2016).

O ciclo de avaliação de desempenho é anual em todas as entidades avaliadas, atendendo ao critério do nível de maturidade (1) Inicial. 
A avaliação de desempenho deve ser realizada em periodicidade adequada para que os empregados tenham feedback tempestivo a respeito de sua atuação na realização dos objetivos da entidade e façam os ajustes necessários para atender às expectativas da organização (COSO, 2013b). A adequação da frequência é questão de julgamento, e cada organização pode definir qual é a periodicidade adequada levando em consideração fatores como a dinâmica da sua área de atuação e os custos do processo de avaliação de desempenho; não obstante, admite-se como pressuposto que, quanto mais frequente o feedback, melhor o alinhamento entre a conduta dos empregados e as expectativas de desempenho da organização.

Quanto à avaliação de desempenho, todas as entidades estudadas instituíram processo de avaliação e observam sistemática semelhante. Não obstante, há oportunidades de melhoria. Cabe observar que apenas o MAPA e o INCRA incluíram a conduta ética entre os fatores de avaliação. Nas três entidades, a avaliação de desempenho da alta gerência e da direção executiva restringe-se aos indicadores de desempenho institucional. Enquanto, no MAPA e no INCRA, as normas definem metas de desempenho em níveis de entidade, equipe e indivíduo, a CONAB não prevê metas de desempenho. O MAPA e o INCRA realizam a avaliação de desempenho com foco no valor da parcela variável da remuneração dos empregados. As normas do MAPA e da CONAB prescrevem a realização de capacitação de empregados com baixo desempenho. Apenas na CONAB o baixo desempenho pode influir no processo de promoção. Em todas as entidades, o ciclo de avaliação de desempenho é anual.

Com base na avaliação, é possível identificar os riscos e recomendações para aprimorar o ambiente de CI das entidades estudadas para a subdimensão Avaliação de Desempenho. Os riscos identificados que dizem respeito somente a CONAB são: 1) A avaliação de desempenho não promove a ética e os valores esperados do comportamento dos empregados da entidade. Recomendação: incluir a conduta ética entre os fatores da avaliação de desempenho; 2) Os empregados não possuem desempenho adequado na realização dos objetivos da entidade em razão da ausência de metas. Recomendação - Definir metas de desempenho em nível de entidade, metas para as unidades e subunidades organizacionais e metas individuais para os empregados da entidade.

Já os riscos identificados para as três organizações analisadas são: 1) Corpo diretivo e alta gerência não recebem feedback a respeito do seu desempenho na realização dos objetivos da entidade. Recomendação: desenvolver procedimentos para a avaliação de desempenho do corpo diretivo e alta gerência da entidade; 2) As sanções e recompensas relacionadas à 
avaliação de desempenho não representam incentivo eficaz para que os empregados tenham desempenho adequado na realização dos objetivos da entidade. Recomendação do INCRA: vincular recompensas e sanções de caráter administrativo e disciplinar à avaliação de desempenho da entidade; da CONAB: estabelecer parcela variável à remuneração dos empregados, vinculada à avaliação de desempenho da entidade; e das três entidades (MAPA, INCRA, CONAB): incluir a movimentação dos empregados no sistema de recompensas e sanções da entidade; 3) Empregados recebem feedback intempestivo a respeito do seu desempenho na realização dos objetivos da entidade - Aumentar a frequência da avaliação de desempenho.

O Quadro 18 apresenta o resultado final dos procedimentos de avaliação do nível de maturidade do ambiente de controle nas entidades estudadas, considerando o peso de cada nível de maturidade, definido pela média dos pesos estabelecidos pelo atendimento dos critérios dentro das variáveis da dimensão.

Quadro 18 - Resultado do nível de maturidade do ambiente de controle interno

\begin{tabular}{|l|l|l|l|}
\hline $\begin{array}{l}\text { Nível de } \\
\text { Maturidade }\end{array}$ & MAPA & INCRA & CONAB \\
\hline (0) Incipiente & $30,8 \%$ & $38,5 \%$ & $30,8 \%$ \\
\hline (1) Inicial & $61,5 \%$ & $50 \%$ & $69,2 \%$ \\
\hline (2) Em formação & $57,7 \%$ & $50 \%$ & $26,9 \%$ \\
\hline (3) Estabelecido & $26,9 \%$ & $26,9 \%$ & $34,6 \%$ \\
\hline Avaliação & (2) Em formação & (2) Em formação & (1) Inicial \\
\hline
\end{tabular}

Fonte: elaborado pelos autores com base nos dados da pesquisa (2016).

Muito embora as entidades MAPA e INCRA apresentem um resultado "Em formação", observou-se que todas as entidades possuem aspectos necessários de melhoria, a exemplo da disseminação de padrões de ética e a ausência de políticas de investigação da vida pregressa e requisitos de competência para os membros do corpo diretivo, avaliados como incipiente. Analisados individualmente, o MAPA destacou-se na avaliação de desempenho, e a CONAB, na definição de responsabilidades de CI e requisitos de competências para os empregados.

Apesar dos destaques ora mencionados, pode-se afirmar que, no formato no qual se encontram as estruturas de CI para o ambiente de controle, nas três organizações avaliadas, há características que podem dificultar o alcance de um ambiente que propicie um monitoramento constante entre os pares. 
Nesse sentido verificou-se a existência de falhas decorrentes da elaboração de padrões de conduta, ética e valores específicos para cada uma das organizações, em especial no MAPA e INCRA, que são genéricos, e não dispõem de ações de disseminação ampla a todos os colaboradores, o que pode aumentar o risco de condutas em desacordo com os objetivos da organização (McNAMEE; FLEMING, 2007). Outro risco advém da ausência de definição dos requisitos de competências para os seus empregados, que pode resultar na alocação de pessoas com pouca competência ou pessoas com competências incompatíveis com as atribuições e responsabilidades inerentes a funções essenciais para realizar os objetivos dessas entidades (JOHNSTONE et al., 2012; BILHIM, 2012).

Acentuando o risco ao ambiente de controle, verifica-se que não são estabelecidos critérios de independência e competência do corpo diretivo, o que é agravado pelo fato de tais dirigentes não serem avaliados individualmente em seu desempenho. Tampouco existem requisitos de competência específica para ocupar os referidos cargos. Por outro lado, são estabelecidas para os níveis operacionais metas de desempenho, bem como recompensas e sanções por meio de avaliação, demonstrando acentuada segregação de funções para monitorar os colaboradores das organizações.

Assim, com base no preceito do COSO (2013b) de que o CI deve ser conduzido pela alta administração e por seu corpo diretivo de modo que as ações individuais convirjam para os objetivos organizacionais, verifica-se que muitas das características identificadas nas organizações avaliadas acabam sendo válidas apenas para os empregados das estruturas operacionais e não para todos (em especial da alta direção). Isso, por conseguinte, pode dificultar a aderência dos objetivos do ambiente de controle em virtude do possível não comprometimento da alta diretoria e, em especial, da ausência de requisitos de independência e competência para ocupar o cargo designado (SPIRA; PAGE, 2003; McNAMEE; FLEMING, 2007).

Com base nas evidências ora identificadas, o ambiente de CI possivelmente não promoverá o que se espera dele, segundo Rubino, Vitolla e Garzoni (2017): a indução de um comportamento ético, íntegro e moral das pessoas para com a organização. 


\section{CONSIDERAÇÕES FINAIS}

Com o objetivo de analisar o ambiente de CI em organizações públicas por meio de um modelo de maturidade, foram avaliadas três entidades com diferentes funções na administração pública, diferentes estruturas organizacionais e de governança - o MAPA, o INCRA e a CONAB - de forma a avaliar a aderência e validade do instrumento de pesquisa (modelo de maturidade) (OLLAIK; ZILLER, 2012; MINAYO, 2009).

Os resultados apontaram a validade e a utilidade do referido modelo, em especial por permitir recomendações específicas a cada entidade e identificar características comuns, com destaque para aquelas que permeiam toda a lógica de alocação de recursos humanos em cargos de alta direção na administração pública. De forma mais específica, os resultados permitiram diagnosticar falhas no ambiente de controle, especialmente em relação aos destinatários dos padrões de conduta, à disseminação em todos os níveis organizacionais, à independência e à competência do corpo diretivo, bem como à avaliação de desempenho da alta administração.

As falhas ora identificadas podem acarretar falta de aderência e de comprometimento dos empregados para construir um ambiente de controle que vise cumprir os objetivos organizacionais, podendo gerar como consequência, conforme já constado por Johnstone et al. (2012): baixo nível de consciência de controle na organização; comitê de auditoria sem membros independentes; falta de cobrança de um comportamento ético na organização; administração que burla os controles sobre as transações contábeis; e pessoal sem competência para cumprir suas atribuições.

Desse modo, o modelo de maturidade adotado neste estudo avança em relação aos anteriores ao proporcionar não somente um diagnóstico do ambiente de controle interno nas organizações avaliadas, mas também prescrições específicas para cada uma delas, juntamente com outras comuns e gerais que possibilitam a comparações. Adicionalmente, se adotado voluntariamente por entidades da administração pública, poderá permitir a busca de melhores práticas de CI, assim como a transferência de conhecimento e tecnologia para outras entidades interessadas.

Por fim, é importante destacar que este estudo apresenta tão somente um dos componentes propostos pelo COSO (2013a; 2013b) das estruturas de CI (ambiente de controle) e que os resultados estão restritos a essa dimensão, bem como às entidades 
analisadas e aos procedimentos metodológicos adotados. Sugere-se, para estudos futuros, ampliar o modelo de maturidade aqui apresentado, incorporando as práticas do COSO II, por exemplo, e a análise entre organizações semelhantes (ministérios com ministérios, universidades com universidades), de modo a permitir a comparação e a prescrição entre os pares. 


\section{REFERÊNCIAS}

BARDIN, Laurence. Análise de Conteúdo. 70. Ed. São Paulo: Almedina Br, 2011.

BECKER, J.; KNACKSTEDT, R.; PÖPPELBUß, J. Developing Maturity Models for IT Management - A Procedure Model and its Application. Business \& Information Systems Engineering (BISE), v. 1, n. 3, p. 213-222, 2009.

BERNARDI, R. A. Fraud detection: The effect of client integrity and competence and auditor cognitive style. Auditing: A Journal of Practice and Theory, v. 13, n. 2, p. 68-84, 1994.

BILHIM, João. O mérito nos processos de seleção da alta direção da Administração Pública portuguesa: mito ou realidade?. Sequência: estudos jurídicos e políticos (UFSC), v. 33, n. 65, p. 57-78, 2012.

COSO (Committee of Sponsoring Organizations of the Treadway Commission). Internal Control - Integrated Framework: Framework and Appendices. 2013a.

Internal Control - Integrated Framework: Internal Control over External Financial Reporting: A Compendium of Approaches and Examples. 2013b.

COY, David; DIXON, Keith. The Public Accountability Index: crafting a parametric disclosure index for annual reports. The British Accounting Review, v. 36, p. 79-106, 2004.

EXNER, Konrad; ZIMPFER, Raphael; STARK, Rainer. Maturity model and action recommendation: a PSS capability self-assessment tool for companies. Procedia CIRP, v. 64, p. 175-180, 2017.

FADZIL, Faudziah Hanim; HARON, Hasnah; JANTAN, Muhamad. Internal auditing practices and internal control system. Managerial Auditing Journal, v. 20, n. 8, p. 844-866, 2005.

FILGUEIRAS, Fernando. Indo além do gerencial: a agenda da governança democrática e a mudança silenciada no Brasil. Revista de Administração Pública, v. 52, n. 1, p. 71-88, 2018.

GAO (UNITED STATES GENERAL ACCOUNTABILITY OFFICE). Internal Control Management and Evaluation Tool. 2001. Disponível em: <http://www.gao.gov/products/GAO-01-1008G>. Acesso em: 01 jul. 2015. 
GAO (UNITED STATES GENERAL ACCOUNTING OFFICE). Standards for Internal Control in the Federal Government (The Green Book). 2014.

HAY, David. Internal Control: How It Evolved in Four English - Speaking Countries. Accounting Historians Journal, v. 20, n. 1, 1993.

IFAC (INTERNATIONAL FEDERATION OF ACCOUNTANTS). Study 13 - Governance in the Public Sector. 2001.

ITGI (IT GOVERNANCE INSTITUTE). COBIT 4.1: Modelo, Objetivos de Controle, Diretrizes de Gerenciamento, Modelos de Maturidade. 2007.

JENSEN, Michael C. The Modern Industrial Revolution, Exit, and The Failure of Internal Control Systems. The Journal of Finance, v. 58, July, 1993.

JOHNSTONE, Karla M.; GRAMLING, Audrey A.; RITTENBERG, Larry E. Auditing: a risk-based approach to conducting a quality audit. 9 Ed. Boston: Cengage Learning, 2012.

LOPES JÚNIOR, Elias Pereira et al. Influência da Corrupção nos Gastos das Empresas Estatais. Revista de Administração Pública, Early View, 2018.

MCNAMEE, Michael John; FLEMING, Scott. Ethics audits and corporate governance: The case of public sector sports organizations. Journal of Business Ethics, v. 73, n. 4, p. 425437, 2007.

MARTINS, Norberto M. Ensaio sobre a "nova" travessia. 2015. Disponível em: <http://www.ie.ufrj.br/images/pesquisa/publicacoes/discussao/2015/TD_IE_021_2015_MAR TINS-v. fin.pdf >. Acesso em: 01 mai. 2016.

MINAYO, M. C. de S. Construção de indicadores qualitativos para avaliação de mudanças. Revista Brasileira de Educação Médica, v. 33, n. 1, p. 83-91, 2009.

OLLAIK, L. G.; ZILLER, H. M. Concepções de validade em pesquisas qualitativas. Educação e Pesquisa, v. 38, n. 1, p. 229-241, 2012.

PÖPPELBUß, Jens; RÖGLINGER, Maximilian. What makes a useful maturity model? A framework of general design principles for maturity models and its demonstration in business process management. In: EUROPEAN CONFERENCE ON INFORMATION SYSTEMS. Anais... Helsinque, Finlândia, 2011. 
PULLEN, William. A public sector HPT maturity model. Performance Improvement, v. 46, n. 4, p. 9-15, 2007.

RICHARDSON, R. J. et al. Pesquisa Social: métodos e técnicas. 3 Ed. São Paulo: Atlas, 2015.

RUBINO, Michele; VITOLLA, Filippo. Internal control over financial reporting: opportunities using the COBIT framework. Managerial Auditing Journal, v. 29, n. 8, p. 736-771, 2014.

; GARZONI; Antonello. The impact of an IT governance framework on the internal control environment. Records Management Journal, v. 27, n. 1, p. 19-41, 2017.

SPIRA, Laura F.; PAGE, Michael. Risk management: The reinvention of internal control and the changing role of internal audit. Accounting, Auditing \& Accountability Journal, v. 16, n. 4, p. 640-661, 2003.

WANDERLEY, Carlos Alexandre Nascimento; FONSECA, Ana Carolina Pimentel Duarte da; DE PAULA, Helmut Alexandre. Controles Internos no Setor Público à Luz da Estrutura do COSO: O Caso de um Órgão de Compra da Marinha do Brasil. ConTexto, v. 15, n. 30, 2015 .

WHITTINGTON, Ray; PANY, Kurt. Principles of auditing \& other assurance services. 18 Ed. McGraw-Hill/Irwin, 2012. 


\section{APÊNDICE 1 - DOCUMENTAÇÃO FORNECIDA PELAS ORGANIZAÇÕES PARA AVALIAÇÃO DA DIMENSÃO - AMBIENTE DE CONTROLE}

\section{Ministério da Agricultura, Pecuária e Abastecimento - MAPA}

- $\quad$ Organograma MAPA

- $\quad$ Decreto 8.492/2015 - Estrutura regimental MAPA

- Regimentos internos dos órgãos que integram a estrutura do MAPA

- Portaria 604/2009 - Regimento interno da comissão de ética do MAPA

- $\quad$ Plano de trabalho da comissão de ética, 2015

- Relatório de atividades da comissão de ética, 2014

- $\quad$ Fluxo de processos de apuração ética

- Portaria 1.180/2012 - Critérios de seleção para ocupantes de cargos DAS 1, 2 e 3

- Portaria 482/2012 - Ações de educação continuada

- Portaria 499/2012 - Critérios e procedimentos para a avaliação de desempenho para fins de concessão das gratificações dos servidores do MAPA

- $\quad$ Edital 1/2014 - Processo de remoção de servidores do MAPA

- $\quad$ Plano estratégico 2006-2015

- $\quad$ Cadeia de valor - Macroprocessos do MAPA

- Portaria 423/2005 - Institui o processo de planejamento e gestão estratégica

- Portaria SE 1.674/2015 - Criação do Grupo Executivo de Controle de Risco Operacional - GECRO

- $\quad$ Relatório de gestão MAPA, exercícios 2013 a 2015

- $\quad$ Relatório anual de auditoria de contas do MAPA (CGU), exercícios 2013 e 2014

\section{Instituto Nacional de Colonização e Reforma Agrária - INCRA}

- $\quad$ Regimento interno do INCRA

- Organograma INCRA

- Portaria 586/2010 - Regimento interno da comissão de ética do INCRA

- Lei 10.550/2002 e Lei 11.090/2005 - Plano da carreira geral INCRA e Perito Federal Agrário

- Instrução Normativa 78/2014 - Participação dos servidores do INCRA em eventos de capacitação

- Portaria MDA n ${ }^{\circ}$ 26/2012 - critérios e procedimentos para a avaliação de desempenho para fins de concessão das gratificações dos servidores do INCRA

- $\quad$ Portaria 236/2014 - Metas globais de desempenho

- Norma de Execução 5/2001 - Critérios de avaliação de desempenho para fins de promoção dos servidores do INCRA

- $\quad$ Plano estratégico MDA/INCRA 2013-2014

- $\quad$ Plano estratégico MDA/INCRA 2015-2018

- $\quad$ Relatório de gestão INCRA, exercícios 2013 a 2015

- $\quad$ Relatório anual de auditoria de contas do INCRA (CGU), exercícios 2013 e 2014 


\section{Companhia Nacional de Abastecimento - CONAB}

- Organograma CONAB

- $\quad$ Estatuto social da CONAB (NOC 10.102)

- $\quad$ Regimento interno da CONAB (NOC 10.104)

- $\quad$ Regimento do conselho disciplinar (NOC 10.403)

- $\quad$ Processo de apurações disciplinares (NOC 10.401)

- $\quad$ Política de governança corporativa e integridade (NOC 10.111)

- $\quad$ Regulamentos de pessoal (NOC 10.105 e 10.106)

- $\quad$ Plano de cargos, carreiras e salários, 2009

- Política de treinamento, desenvolvimento e educação de recursos humanos (NOC 60.103)

- $\quad$ Política de gestão do desempenho 2015

- $\quad$ Política de transferência de empregados (NOC 60.106)

- Plano estratégico CONAB

- $\quad$ Relatório de gestão CONAB, exercícios 2013 e 2014

- $\quad$ Relatório anual de auditoria de contas da CONAB (CGU), exercícios 2013 e 2014

\footnotetext{
i Internal control is a process, effected by an entity's board of directors, management, and other personnel, designed to provide reasonable assurance regarding the achievement of objectives relating to operations, reporting, and compliance.

ii $[\ldots]$ the policies and procedures established to provide reasonable assurance that specific entity objectives will be achieved.

iii A maturity model consists of a sequence of maturity levels for a class of objects [...] represents an anticipated, desired, or typical evolution path of these objects shaped as discrete stages. Typically, these objects are organizations or processes.

iv To ensure effective communication with stakeholders, public sector entities may: [...] set in place clear procedures for employees to voice concerns or complaints about maladministration, breaches of the law or ethical concerns, in an environment where they will be supported and protected from reprisals.

${ }^{v}$ As competências técnicas definidas no âmbito do Plano de Cargos, Carreiras e Salários da Conab classificamse em: Gerais; Apoio/Suporte Administrativo; Informações e Operações; Recursos Humanos; Administrativas; Licitações; Tecnologia da Informação; Planejamento e Avaliação; Políticas Públicas; Jurídicas; Financeiras Contábeis; Assessoria; Auditoria Interna; Comunicação.
} 